\title{
$D$ box and KEN box motifs in budding yeast Hsl1p are required for APC-mediated degradation and direct binding to Cdc20p and Cdh1p
}

\author{
Janet L. Burton and Mark J. Solomon ${ }^{1}$ \\ Department of Molecular Biophysics and Biochemistry, Yale University, New Haven, Connecticut 06520-8114, USA
}

The precise order of molecular events during cell cycle progression depends upon ubiquitin-mediated proteolysis of cell cycle regulators. We demonstrated previously that Hsl1p, a protein kinase that inhibits the Swe1p protein kinase in a bud morphogenesis checkpoint, is targeted for ubiquitin-mediated turnover by the anaphase-promoting complex (APC). Here, we investigate regions of Hsl1p that are critical both for binding to the APC machinery and for APC-mediated degradation. We demonstrate that Hsl1p contains both a destruction box (D box) and a KEN box motif that are necessary for Hsl1p turnover with either APC ${ }^{\mathrm{Cdc20}}$ or APC $^{\text {Cdh1 }}$. In coimmunoprecipitation studies, the D box of full-length Hsl1p was critical for association with Cdc20p, whereas the KEN box was important for association with Cdh1p. Fusion of a 206-amino-acid fragment of Hsl1p containing these motifs to a heterologous protein resulted in APC-dependent degradation of the fusion protein that required intact D box and KEN box motifs. Finally, this bacterially expressed Hsl1p fusion protein interacted with $\mathrm{Cdc} 20 \mathrm{p}$ and $\mathrm{Cdh} 1 \mathrm{p}$ either translated in vitro or expressed in and purified from insect cells. Binding to Cdc20p and Cdh1p was disrupted completely by a D box/KEN box double mutant. These results indicate that D box and KEN box motifs are important for direct binding to the APC machinery, leading to ubiquitination and subsequent protein degradation.

[Key Words: Cdc20p; Cdh1p; KEN box; destruction box; ubiquitination; anaphase-promoting complex]

Received June 11, 2001; revised version accepted July 31, 2001.

Ubiquitin-mediated protein degradation is necessary for the linear progression of molecular events during the cell cycle. Protein ubiquitination and subsequent degradation by the $26 \mathrm{~S}$ proteasome is required for the initiation of DNA replication, the onset of anaphase, and for mitotic exit (for reviews, see King et al. 1996; Peters 1999; Zachariae and Nasmyth 1999). The ubiquitin pathway is a multi-step process in which the 76-amino-acid ubiquitin molecule is activated by an E1 enzyme, transferred to an E2 enzyme, and then attached covalently to the protein substrate either directly or in conjunction with an E3 enzyme (ubiquitin ligase) (for reviews, see Ciechanover 1994; Hochstrasser 1996). Proteins destined to be degraded are subject to multiple rounds of ubiquitin attachment (polyubiquitination) and are then proteolyzed by the $26 \mathrm{~S}$ proteasome. The E3 or ubiquitin ligase is involved in protein substrate recognition and thereby confers specificity to the ubiquitination reaction (for reviews, see Ciechanover 1994; Hochstrasser 1996).

${ }^{1}$ Corresponding author.

E-MAIL Mark.Solomon@Yale.edu; FAX (203) 432-3104.

Article and publication are at http://www.genesdev.org/cgi/doi/10.1101/ gad.917901.
The SCF (Skplp-cullin-F-box) ubiquitin ligases are a family of multi-subunit E3s that are responsible for ubiquitination of cell cycle regulators at the $\mathrm{G}_{1}-\mathrm{S}$ phase transition (for reviews, see King et al. 1996; Krek 1998; Peters 1998). SCF complexes have common Skp1 and cullin subunits, but distinct F-box protein subunits that contain either a WD40 domain or a leucine-rich repeat domain that binds directly to phosphorylated SCF substrates (for reviews, see Krek 1998; Patton et al. 1998; Peters 1998). In Saccharomyces cerevisiae, the $\mathrm{G}_{1}$-cyclins, Cln $1 \mathrm{p}$ and $C \ln 2 \mathrm{p}$, bind $\mathrm{SCF}^{\mathrm{Grr} 1}$ (Deshaies et al. 1995; Skowyra et al. 1999), whereas the Cdc28p kinase inhibitor, Siclp, has been shown to bind SCF ${ }^{\text {Cdc4 }}$ (Feldman et al. 1997; Skowyra et al. 1997; Verma et al. 1997), where Grrlp and Cdc4p are the F-box components of these SCFs.

The anaphase-promoting complex (APC), or cyclosome, another multi-subunit E3, is responsible for the ubiquitination of cell regulators at the metaphase-anaphase and mitosis- $\mathrm{G}_{1}$ transitions (for review, see Zachariae and Nasmyth 1999). The APC is comprised of a core complex of proteins and two WD40-containing proteins, Cdh1 (called Cdh1p or Hctlp in S. cerevisiae) and $\mathrm{Cdc} 20$, that bind to, and have been proposed to ac- 
tivate, the APC (Schwab et al. 1997; Visintin et al. 1997; Fang et al. 1998b; Kramer et al. 1998; Lim et al. 1998; Zachariae et al. 1998; Kotani et al. 1999). Cdc20 binds the APC $\left(\mathrm{APC}^{\mathrm{Cdc} 2 \mathrm{O}}\right)$ during mitosis. $\mathrm{APC}^{\mathrm{Cdc} 20}$ is required for the degradation of the anaphase inhibitors known as the securins (Pds1p in S. cerevisiae and Cut2p in Schizosaccharomyces pombe), thereby triggering sister chromatid separation (Cohen-Fix et al. 1996; Funabiki et al. 1996; Stratmann and Lehner 1996; Yamamoto et al. 1996; Ciosk et al. 1998; Zou et al. 1999; Zur and Brandeis 2001). Cdh1 binds to the APC (APC $\left.{ }^{\mathrm{Cdh} 1}\right)$ in late mitosis and $G_{1}$ and is responsible for ubiquitination of the mitotic cyclins (Clb1-4p in S. cerevisiae) during these cell cycle phases (Schwab et al. 1997; Visintin et al. 1997; Kramer et al. 1998; Zachariae et al. 1998; Jaspersen et al. 1999). APC ${ }^{\text {Cdh1 } 1}$ is also responsible for the degradation of $\mathrm{Cdc} 20$, thereby restricting $\mathrm{APC}^{\mathrm{Cdc} 20}$ activity to a narrow window from $\mathrm{G}_{2}$ when $\mathrm{Cdc} 20$ is synthesized to late mitosis when Cdc20 is degraded by APC $^{\mathrm{Cdh} 1}$ (Fang et al. 1998b; Prinz et al. 1998; Shirayama et al. 1998). In contrast, Cdh1 levels remain relatively constant during the cell cycle, but phosphorylation of Cdh1 by the mitotic kinase Cdc2 (Cdc28p in S. cerevisiae) blocks Cdh1 binding to the APC, thereby preventing $\mathrm{APC}^{\mathrm{Cdh} 1}$ activity during $S, G_{2}$, and $M$ phases when $\mathrm{Cdc} 2 / \mathrm{Cdc} 28 \mathrm{p}$ activity is high (Zachariae et al. 1998; Jaspersen et al. 1999; Shirayama et al. 1999; Blanco et al. 2000; Listovsky et al. 2000).

Two degradation motifs have been identified in APC substrates. The destruction box (D box), with the consensus sequence $\mathrm{R}-\mathrm{X}-\mathrm{X}-\mathrm{L}-\mathrm{X}-\mathrm{X}-\mathrm{X}-\mathrm{X}-\mathrm{N} / \mathrm{D} / \mathrm{E}$, is important for the degradation of most APC substrates /Glotzer et al. 1991; for review, see Zachariae and Nasmyth 1999). Recently, human Cdc20 (hCDC20), which lacks a D box, was found to contain a new degradation signal called a 'KEN box' with the consensus sequence K-E-N-X-X-X$\mathrm{D} / \mathrm{N}$ that was critical for its degradation by $\mathrm{APC}^{\mathrm{Cdh} 1}$ (Pfleger and Kirschner 2000). Subsequently, a few other APC substrates containing both KEN box and D box motifs have been identified. These APC substrates are human CDC6, a protein required for DNA replication, human securin, and the mitotic cyclin A in Drosophila melanogaster (Peterson et al. 2000; Jacobs et al. 2001; Zur and Brandeis 2001). Functional KEN boxes in yeast proteins have not yet been reported.

Because direct interactions between Cdc20 or Cdh1 with APC substrates have not been demonstrated, generally these proteins are believed to activate the APC, possibly by inducing allosteric changes in core APC subunits leading to specific substrate binding and ubiquitination. However, indirect evidence for substrate binding has led others to suggest, by analogy to the F-box proteins of the SCFs, that Cdc20 and Cdh1 may bind and target protein substrates to the APC (Schwab et al. 1997; Visintin et al. 1997; Shirayama et al. 1998; Burton and Solomon 2000; Ohtoshi et al. 2000; Sorensen et al. 2001).

We found previously that Hsllp, a $170-\mathrm{kD}$ budding yeast protein kinase that negatively regulates the Swelp protein kinase in a bud morphogenesis checkpoint pathway (Lew and Reed 1995; Barral et al. 1999; McMil- lan et al. 1999; Shulewitz et al. 1999), is degraded via the APC (Burton and Solomon 2000). Like most APC-substrates, Hsllp contains a D box that is important for its degradation. Hsllp associates with both Cdc20p and Cdh1p based on both two-hybrid assays and coimmunoprecipitation from yeast extracts, indicating that it might interact directly with these proteins (Burton and Solomon 2000). Given these findings, we believed that Hsllp might serve as a useful model substrate for understanding how proteins destined for degradation are recognized by the APC.

In this study we set out to understand which domains of Hsllp are important for both recognition and turnover by the APC machinery. We noticed that Hsllp contains a potential KEN box and were interested in addressing the following questions using Hsllp as a model APC substrate: 1) Do KEN boxes serve as degradation signals in yeast? 2) Can Hsllp bind directly to Cde20p and/or Cdhlp? 3) What is the role of the D box and/or KEN box in APC recognition? We discuss a model for substrate recognition by the APC machinery.

\section{Results}

Hs11p degradation requires intact $D$ box and KEN box motifs

Previously, we demonstrated that the APC-dependent degradation of Hsllp requires an intact destruction box (D box) motif (Burton and Solomon 2000). Following the recent identification of the KEN box (KENxxxN/D; bold indicates conserved and mutated residues) as a second APC-degradation signal important for $\mathrm{APC}^{\mathrm{Cdh} 1}$-mediated degradation (Pfleger and Kirschner 2000), we scanned the Hsllp sequence and found a potential KEN box motif that closely matched that of hCDC20 (Fig. 1A). To determine if this sequence influences APC-mediated degradation of Hsllp, the conserved amino acid residues (underlined in Fig. 1A) were mutated to alanines. The stabilities of full length HsllpHA or of Hsllp-HA containing a mutated D box (RAALSDITN to AAAASDITA) (Hsllp $\left.{ }^{\text {mdb }}-\mathrm{HA}\right)$, a mutated KEN box (Hsllp $\left.{ }^{\text {mkb}}-\mathrm{HA}\right)$, or both mutations $\left(\mathrm{Hsll} \mathrm{p}^{\mathrm{mdb} / \mathrm{mkb}}-\mathrm{HA}\right)$ were investigated in $\mathrm{G}_{1}$, a stage of the cell cycle when $\mathrm{APC}^{\mathrm{Cdh} 1}$ is active. Cells were arrested in $G_{1}$ with $\alpha$-factor and induced to express the different isoforms of Hsllp-HA by galactose induction. Then, expression was terminated by the addition of glucose and cycloheximide to the medium. Levels of the different forms of Hsllp-HA were monitored by immunoblot analysis with anti-HA antibodies (Fig. 1B). As shown previously (Burton and Solomon 2000), wild-type Hsllp-HA was unstable in the presence of $\mathrm{APC}^{\mathrm{Cdh} 1}$, but stable in a strain (cdc23-1) mutated for a core APC subunit (Fig. 1B, top row). In contrast, Hsllp $\mathrm{p}^{\mathrm{mdb}}-\mathrm{HA}$ containing the mutated $\mathrm{D}$ box was relatively stable even in the presence of an active APC (Fig. 1B, second row, left panel). Similarly, mutation of the putative KEN box (Hsllp $\left.{ }^{\text {mkb}}-\mathrm{HA}\right)$ or of both motifs $\left(\mathrm{Hsll}^{\mathrm{mdb} / \mathrm{mkb}}-\mathrm{HA}\right)$ also resulted in Hsllp stabilization (Fig. 1B, third and 
A

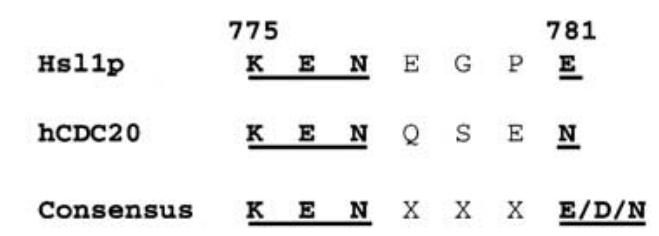

B
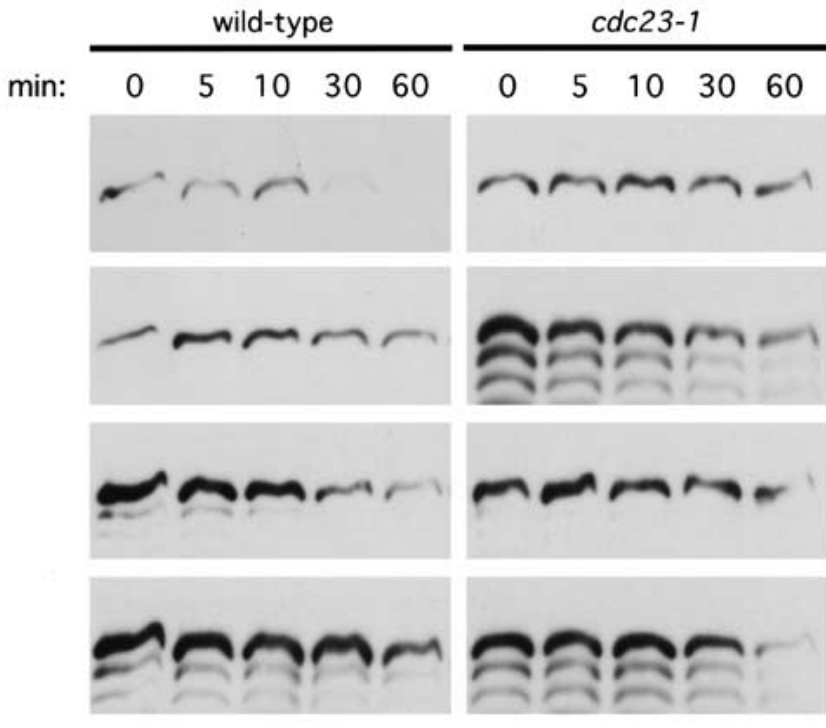

1

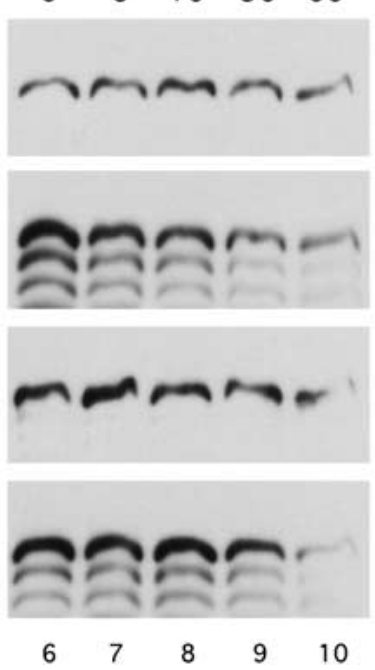

HsI 1 p-HA

$H s 11 p^{m d b}-H A$

Hsl1p mkb-HA

$\mathrm{Hsl1p}^{\mathrm{mdb} / \mathrm{mkb}}$-HA
Figure 1. Hsllp has both a D box and a KEN box and both are necessary for APCmediated degradation in $\mathrm{G}_{1}$. (A) Hsllp has a putative KEN box located at amino acids 775-781. The human CDC20 (hCDC20) KEN box and consensus sequence (Pfleger and Kirschner 2000) are shown for comparison. (B) $\mathrm{APC}^{\mathrm{Cdh} 1}$-mediated degradation of Hsllp-HA in $\mathrm{G}_{1}$-arrested cells requires both a D box and a KEN box. Cells were arrested in $\mathrm{G}_{1}$ with $\alpha$-factor (100 ng/ $\mathrm{mL}$ ) and induced to express GAL-HSL1$H A$ (YJB123 and YJB125), GAL-HSL1 ${ }^{\mathrm{mdb}}$ $H A$ (YJB229 and YJB270), GAL-HSL1 ${ }^{\mathrm{mkb}}$ $H A$ (YJB257 and YJB271) and GAL$H S L 1^{\mathrm{mdb} / m k b}-H A$ (YJB258 and YJB272) by the addition of galactose. Cells were shifted to $37^{\circ} \mathrm{C}$ to inactivate the APC in cdc23-1 strains. Proteins levels were monitored by immunoblotting with antiHA antibodies at the indicated times following termination of Hsllp expression. fourth rows, left panels). These results indicate that KEN boxes are recognized by the APC machinery in yeast and that both a D box and a KEN box are necessary for maximal rates of Hsllp degradation by APC ${ }^{C d h 1}$.

Given the similarities between Cdh1p and Cdc20p, we were interested in whether $\mathrm{APC}^{\mathrm{Cdc} 20}$ could also mediate Hsllp degradation. Although normally Hsllp is degraded late in mitosis (Burton and Solomon 2000), we found that Hsllp-HA was stable in anaphasearrested cells expressing a nondegradable form of Clb2p (data not shown). Therefore, we assessed Hsllp stability in $G_{1}$, a point in the cell cycle at which Hsllp is known to be unstable (Fig. 1B; Burton and Solomon 2000). In order to eliminate $\mathrm{APC}^{\mathrm{Cdh} 1}$ activity and look only at APC ${ }^{\mathrm{Cdc20}}$ activity in $\mathrm{G}_{1}$, we used $c d h 1 \Delta$ cdc28-13 cells with or without an integrated copy of GAL-CDC20myc. $c d h 1 \Delta$ cells are viable, but have elevated levels of Clb2p, resulting in an inefficient $G_{1}$ arrest with $\alpha$-factor (Schwab et al. 1997; Visintin et al. 1997). The conditional cdc28-13 allele was used to arrest cells in $\mathrm{G}_{1}$ by shifting cells to the restrictive temperature (LoRincz and Reed 1986).

Using this strain background, we examined the stabilities of wild-type and mutant forms of Hsllp-HA with or without Cdc20-pmyc expression. $\mathrm{G}_{1}$-arrested cells were induced to express GAL-HSL1-HA, GAL-HSL1 ${ }^{m d b}-H A$, or GAL-HSL1 $1^{m k b}-H A$ either without or with $G A L-$ CDC20-myc expression by the addition of galactose to the medium. Expression of the different Hsllp-HA proteins (and of Cdc20p-myc in the indicated strains) was terminated by the addition of glucose/cycloheximide to the cells; protein levels were assessed by quantitative immunoblot analysis using anti-HA antibodies (Fig. 2A; see Materials and Methods). Wild-type Hsllp-HA was relatively stable in the $c d h 1 \Delta c d c 28-13$ cells with most of the protein still present after $60 \mathrm{~min}$ (Fig. 2A, filled circles). However, Hsllp-HA was unstable with a halflife of $\sim 30 \mathrm{~min}$ in cells overexpressing Cdc20p-myc, presumably due to $\mathrm{APC}^{\mathrm{Cdc} 20}$-mediated degradation (Fig. 2A, cf. open circles with closed circles). In contrast, Hsllp ${ }^{\text {mdb }}-\mathrm{HA}$ and Hsllp ${ }^{\text {mkb }}-\mathrm{HA}$ were relatively stable in cells expressing Cdc20p-myc (Fig. 2A, open triangles and squares). FACS analysis confirmed that these cells remained arrested in $G_{1}$ (Fig. 2B). We have also observed that most of the Hsllp-HA is degraded as cells progress from mitosis to $\mathrm{G}_{1}$ in $c d h 1 \Delta$ cells (data not shown), indicating that endogenous Cdc20p is able to degrade Hsllp in late mitosis. These results indicate that Hsllp degradation can be mediated both by $\mathrm{APC}^{\mathrm{Cdc} 20}$ and by $\mathrm{APC}^{\mathrm{Cdh} 1}$ and that both D box and KEN box motifs are required in both cases.

\section{Hsl1p degradation motifs influence association with the APC machinery}

Next, we examined the importance of the D box and the KEN box for the association of Hsllp with Cdc20p and Cdhlp in a coimmunoprecipitation assay. We showed previously that the D box in Hsllp was important for association with Cdc20p, but not with Cdh1p (Burton and Solomon 2000). Full-length Hsllp-HA, Hsllp ${ }^{\mathrm{mdb}}$ 
A

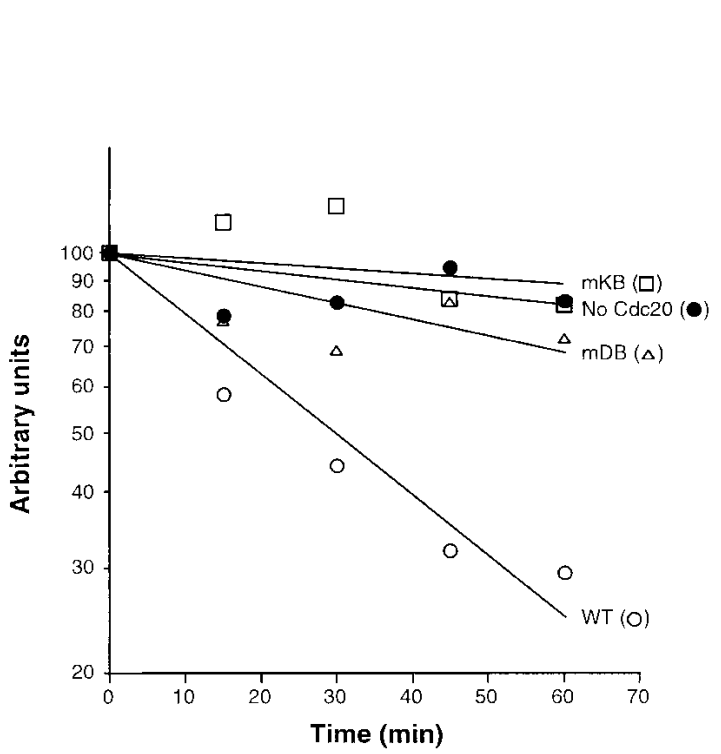

B
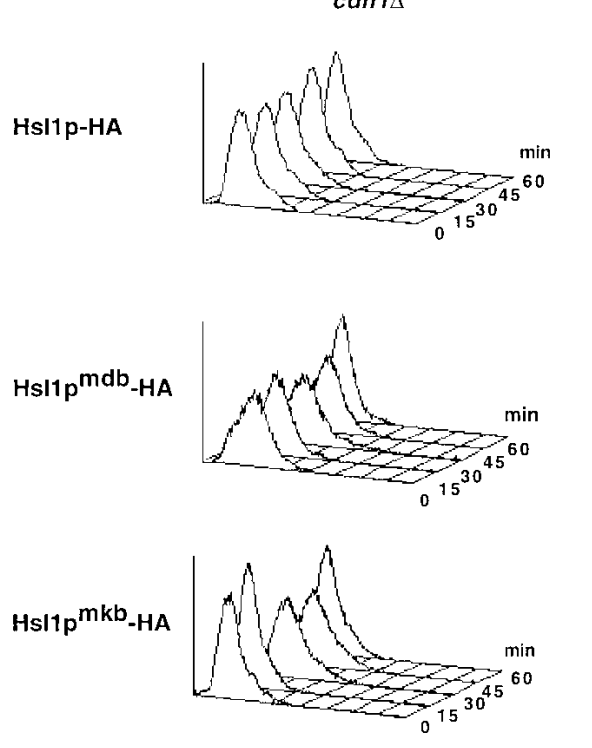

cdh1 $\triangle$ GAL-CDC20-myc
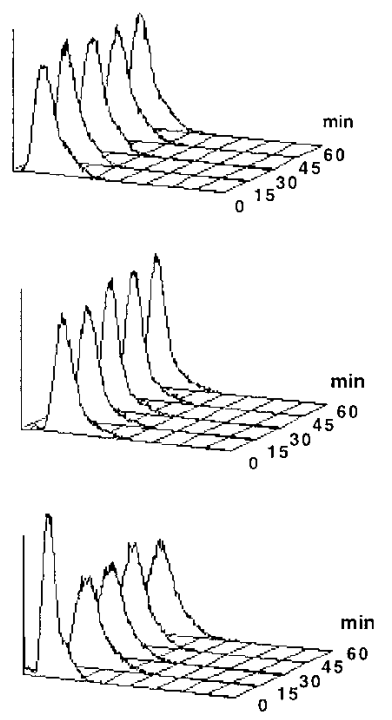

Figure 2. Cdc20p can promote the degradation of Hs11p-HA in $\mathrm{G}_{1}$. (A) cdh1s cdc28-13 cells with (YJB367, YJB368 and YJB380) or without $G A L-C D C 20-m y c$ (YJB366, YJB377 and YJB379) were arrested in $\mathrm{G}_{1}$ by inactivation of $c d c 28-13$ at $37^{\circ} \mathrm{C}$, then galactose was added to induce expression of GAL-HSL1-HA (YJB366 and YJB367), GAL-HSL1 ${ }^{\text {mdb }}-H A$ (YJB377 and YJB378) and GAL-HSL1 ${ }^{\text {mkb }}-H A$ (YJB379 and YJB380) and of GAL-CDC20-myc. Levels of wild-type and mutant forms of Hsllp-HA were monitored at specified times after glucose/cycloheximide addition by quantitative immunoblotting with anti-HA antibodies (see Materials and Methods). Filled and open circles represent Hsllp-HA without or with Cdc20-myc expression, respectively. The ratios of Hsllp ${ }^{\text {mdb }}-\mathrm{HA}$ (open triangles) and

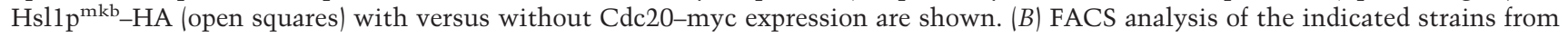
the experiment in $(A)$.

HA, Hsllp $\mathrm{p}^{\mathrm{mkb}}-\mathrm{HA}$, or Hsllp $\mathrm{p}^{\mathrm{mdb} / \mathrm{mkb}}$ were co-overexpressed in yeast with either GST-Cdc20p or GSTCdhlp. The different Hsllp-HA proteins were then immunoprecipitated (IP) from cell extracts using anti-HA antibodies. Coimmunoprecipitation of GST-Cdc20p or GST-Cdhlp was examined by immunoblot analysis with anti-GST antibodies (Fig. 3A). As found previously, both GST-Cdc20p and GST-Cdh1p coimmunoprecipitated with wild-type Hsllp-HA (Fig. 3A, lower panels, lanes 2 and 7), whereas little or no GST-Cdc20p or GSTCdhlp was detected in control immunoprecipitations from strains lacking an HA-tag (Fig. 3A, lower panels, lanes 1 and 6). Mutation of the D box in Hsllp compromised association with Cdc20p, but had little effect on Cdh1p association (Fig. 3A, lower panels, lanes 3 and 8; see also Figs. 5B, 6 and $8 \mathrm{C}$, below). In contrast, mutation of the KEN box had little effect on Cdc20p association, but eliminated Cdh1p association (Fig. 3A, lower panels, lanes 4 and 9). Neither GST-Cdc20p nor GST-Cdh1p associated with $\mathrm{Hsllp} \mathrm{p}^{\mathrm{mdb} / \mathrm{mkb}}$ (Fig. 3A, lower panels, lanes 5 and 10). These results indicate that in the context of full-length Hsllp-HA, the D box is important for association with Cdc20p, whereas the KEN box is important for association with Cdhlp. Since both motifs must be present for efficient degradation (Figs. 1B and 2A), these results also indicate that association, though necessary, is not sufficient to promote degradation. Though suggestive, it is important to note that these data do not show direct binding of Hsllp to Cdc20p and Cdhlp. It is possible that another yeast protein, such as a core APC subunit, serves as a bridge between Hsllp and Cdc20p or Cdh1p in the immunoprecipitates.

To test the generality of these findings, we tested whether Clb2p, a mitotic cyclin that is a well-documented APC substrate (Irniger et al. 1995; Schwab et al. 1997; Jaspersen et al. 1998; Zachariae et al. 1998) could associate also with Cdc20p and Cdhlp by coimmunoprecipitation studies. Clb2p-HA or Clb2 $\mathrm{p}^{\mathrm{mdb}}-\mathrm{HA}$ were cooverexpressed with GST-Cdc20p or GST-Cdh1p and analyzed as for Hsllp-HA (Fig. 3B). Mutation of this D box stabilizes Clb2p (Irniger et al. 1995; Schwab et al. 1997; Jaspersen et al. 1998; Zachariae et al. 1998). Clb2pHA was able to coimmunoprecipitate both GST-Cdc20p and GST-Cdh1p (Fig. 3B, lower panels, lanes 2 and 5), but these proteins were not present in immunoprecipitates from strains lacking an HA-tag (Fig. 3B, lower panels, lanes 1 and 4). However, coimmunoprecipitation of GST-Cdc20p and GST-Cdh1p was not affected by mutation of the Clb2p D box (Fig. 3B, lower panels, lanes 3 and 6). It is possible that a recently identified KEN box in Clb2p (S. Holloway, pers. comm.) may mediate association of Clb2 $\mathrm{p}^{\mathrm{mdb}}$ with Cdc20p and Cdh1p. It is also possible that the interaction we observed between Cdc20p and $\mathrm{Clb} 2 \mathrm{p}$ may reflect phosphorylation of Cdc20p by Cdc28p, as occurs with CDK2 and human CDC20 /Ohtoshi et al. 2000). These results indicate that the association of APC substrates with Cdc20p and Cdh1p is not unique to Hsllp and that other APC substrates might associate with these proteins, although the requirements for the interactions may differ. 
A

IP Hsl1p-HA:

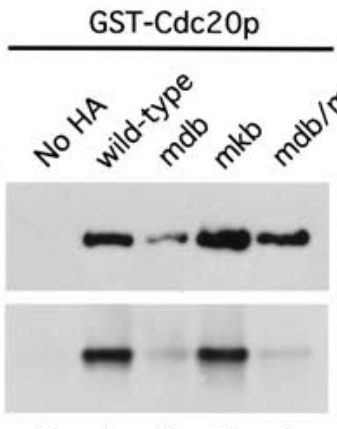

$\begin{array}{lllll}1 & 2 & 3 & 4 & 5\end{array}$

B

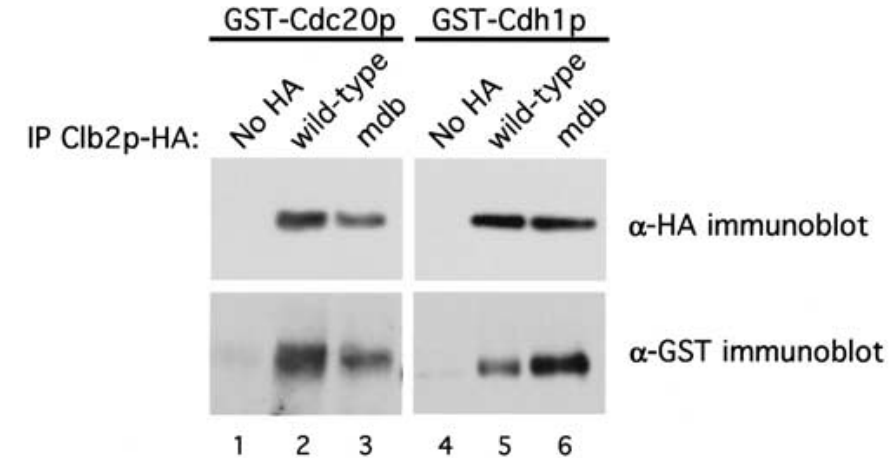

GST-Cdh1p

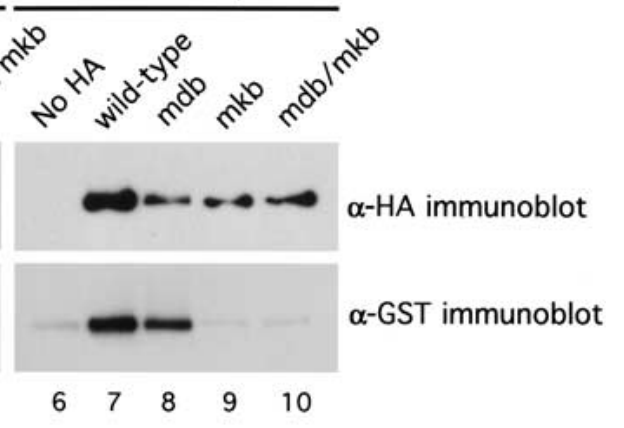
respectively. The different forms of HsllpHA were immunoprecipitated (IP) with antiHA antibodies from extracts of cells coexpressing either GST-Cdc20p or GST-Cdh1p and then probed for the levels of precipitated Hsllp-HA proteins (upper) or GST-Cdc20p and GST-Cdhlp (lower) by immunoblot analysis using anti-HA and anti-GST antibodies, respectively. (Lanes 1-10) Strains YJB221, YJB156, YJB230, YJB259, YJB260, YJB222, YJB218, YJB231, YJB261 and YJB262, respectively. (B) GST-Cdc20p and GSTCdhlp can coimmunoprecipitate with Clb2p-HA. Clb2p-HA was immunoprecipitated with anti-HA antibodies from extracts of cells coexpressing GST-Cdc20p or GSTCdhlp and proteins were monitored by immunoblot analysis as described in $(A)$. (Lanes 1-6) Strains YJB221, YJB275, YJB276, YJB222, YJB277 and YJB278, respectively. Strains lacking an HA tag (YJB221 and YJB222) but expressing GST-Cdc20p or GST-Cdhlp, respectively, were used as negative controls (No HA) in $A$ and $B$. mdb, mutant D box; mkb, mutant KEN box.

Hs11p $p^{667-872}$ can act as a transposable degradation signal

We investigated whether fragments of Hsllp containing both the KEN box and the D box, located at amino acids 775-781 and 828-836, respectively, could serve as portable degradation signals. We started with a 206-aminoacid fragment containing both motifs plus 108 amino acids N-terminal to the KEN box (Hsllp ${ }^{667-872}$; Fig. 4, top row, left panel). The upstream residues were included because of the observation that APC-mediated degradation of hCDC20 requires amino acid residues upstream of the KEN box (Pfleger and Kirschner 2000). Hsllp ${ }^{667-872}$ was fused to the C terminus of the E. coli maltose binding protein (MBP) and expressed in yeast. The stabilities of this fusion protein and of progressively smaller fusion proteins comprising the KEN box and D box were tested in $\mathrm{G}_{1}$-arrested cells to examine $\mathrm{APC}^{\mathrm{Cdh} 1 \mathrm{p}}$-mediated degradation (Fig. 4). MBP alone was found to be stable when expressed in yeast cells (data not shown). MBP-Hsl1p 667-872 $^{6 a s}$ very unstable and was undetectable $15 \mathrm{~min}$ after terminating its synthesis (Fig. 4, top row, middle panel). The instability of MBPHsl1p 667-872 $^{6 a s}$ due to APC-mediated degradation as the protein was stable in $c d c 23-1$ cells (Fig. 4, top row). MBP-Hsllp ${ }^{667-837}$, which removes 35 amino acid residues downstream of the $\mathrm{D}$ box, was also quite unstable; this instability was APC-dependent (Fig. 4, second row). However, truncation of the N-terminal domain upstream of the KEN box greatly stabilized the MBP-Hsllp fusion proteins (MBP-Hsl1 $1^{701-872}$, MBP-Hsllp ${ }^{740-872}$, and MBP-Hsl1p $\mathrm{p}^{764-872}$; Fig. 4, rows 3-7). These results suggest that sequences upstream of the KEN box motif are important for degradation of the fusion protein, although it is not yet clear if this region contains an additional degradation motif or if it provides a structural requirement for KEN box recognition. These results show that fragments of Hsllp can act as transposable degradation signals when fused to MBP. Based on its rapid degradation, we chose MBP-Hsl1p $\mathrm{p}^{667-872}$ for further analysis.

First, we wanted to confirm that the APC-mediated degradation of MBP-Hsllp p67-872 $^{6 a s}$ D box- and KEN box-dependent. The stabilities of MBP-Hsllp ${ }^{667-872}$, MBP-Hsllp ${ }^{667-872 \mathrm{mdb}}, \mathrm{MBP}-\mathrm{Hs} 11 \mathrm{p}^{667-872 \mathrm{mkb}}$, and MBPHsllp $\mathrm{p}^{667-872 \mathrm{mdb} / \mathrm{mkb}}$ were monitored in $\mathrm{G}_{1}$-arrested cells as described for full-length Hsllp. Mutation of either the $\mathrm{D}$ box or KEN box resulted in stabilization of MBPHsllp ${ }^{667-872}$ (Fig. 5A, mdb and $\mathrm{mkb}$ ) and mutation of both motifs resulted in complete stabilization of the fusion protein (Fig. 5A, mdb/mkb). These findings indicate that $\mathrm{APC}^{\mathrm{Cdh} 1}$-dependent degradation of MBPHsllp $\mathrm{p}^{667-872}$ and Hsllp-HA both require a D box and a KEN box.

Next, we tested whether MBP-Hsl1p ${ }^{667-872}$, like Hsllp, could associate with Cdc20p and Cdh1p by coimmunoprecipitation. The different forms of MBPHsllp $\mathrm{p}^{667-872}$ were co-overexpressed with either GST-

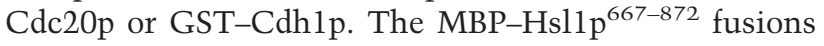
were immunoprecipitated and the levels of coimmunoprecipitating GST-Cdc20p or GST-Cdh1p were analyzed by immunoblot analysis (Fig. 5B, lower panels). We 


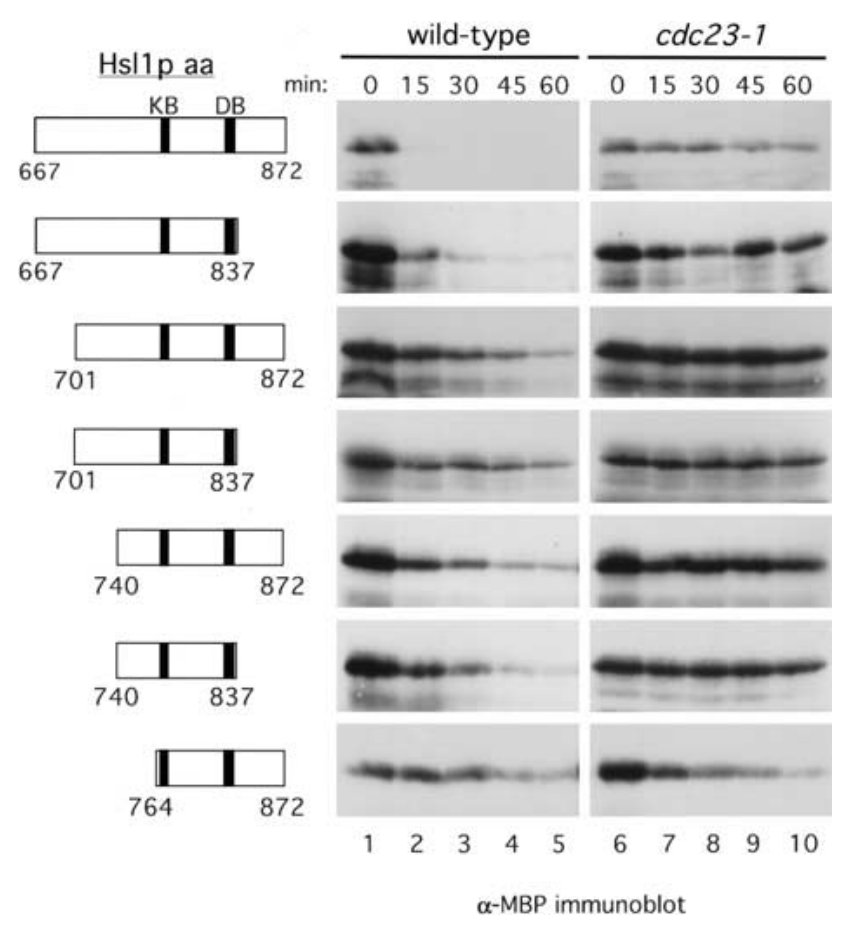

Figure 4. Analysis of Hsllp sequences that can act as transposable APC-dependent degradation signals when fused to the carboxyl terminus of the maltose binding protein (MBP). Left panels, schematic representations of amino acids of Hsllp containing the KEN box and D box motifs (shaded boxes) that were fused to MBP (data not shown). Middle and right panels, stability of MBP-Hsllp proteins in $\mathrm{G}_{1}$-arrested cells. Wild-type and cdc23-1 cells were arrested in $\mathrm{G}_{1}$ with $\alpha$-factor $(100 \mathrm{ng} / \mathrm{mL})$ and then induced to express GAL-MBP-HSL1 ${ }^{667-872}$ (YJB306 and YJB311), GAL-MBP-HSL1667-837 (YJB320 and YJB331), GALMBP-HSL1 $1^{701-872}$ (YJB321 and YJB335), GAL-MBP-HSL1 ${ }^{701-837}$ (YJB329 and YJB336), GAL-MBP-HSL1 ${ }^{740-872}$ (YJB322 and YJB332), GAL-MBP-HSL1 ${ }^{740-837}$ (YJB330 and YJB337) and GAL-MBP-HSL1 ${ }^{764-872}$ (YJB307 and YJB311) fusions by the addition of galactose. Strains were subsequently shifted to $37^{\circ} \mathrm{C}$ to inactivate the APC in the $c d c 23-1$ mutants and the levels of the MBP-Hsllp fusion proteins were monitored by immunoblot analysis with anti-MBP antibodies at the indicated times after glucose/cycloheximide addition to terminate MBP-Hsllp synthesis.

found that GST-Cdc20p had the same specificity of interaction with MBP-Hsllp $\mathrm{p}^{667-872}$ as was observed for full-length Hsllp-HA (cf. Fig. 5B lower panel, lanes 1-5 with Fig. 3A). Mutation of the D box or of both the D box and the KEN box prevented the coimmunoprecipitation of GST-Cde20p (Fig. 5B, lower panel, lanes 3 and $5)$, whereas GST-Cdc20p associated equally well with the wild-type and the KEN box mutant forms of MBP-Hsl1p ${ }^{667-872}$ (Fig. 5B, lower panel, lanes 2 and 4). In contrast, GST-Cdhlp did not associate with MBPHsllp ${ }^{667-872}$ (Fig. 5B, lower panel, lanes 7-10), indicating either that Cdh1p cannot associate well with this domain of Hsllp, or that the combination of the MBP and GST tags and anti-MBP-antibodies interferes with the association. We favor the latter possibility because MBPHsllp ${ }^{667-872}$ is degraded in $G_{1}$-arrested cells in which
APC ${ }^{\mathrm{Cdh} 1}$ activity predominates (Figs. 4A, 5A) and because of direct binding data between MBP-Hsl1p $\mathrm{p}^{667-872}$ and Cdh1p presented below.

\section{Cdc20p and Cdh1p bind directly to Hs11p $p^{667-872}$ in a $D$ box- and KEN box-dependent manner}

To test whether Hsl1p interacts directly with Cdc20p and Cdh1p, we used recombinant MBP-Hsllp $\mathrm{p}^{667-872}$ produced in $E$. coli and purified on amylose resin and $\left[{ }^{35} \mathrm{~S}\right]$ methionine-labeled Cdc20p and Cdh1p translated in vitro in reticulocyte lysates (Fig. 6). MBP and the various MBP-Hsllp proteins on amylose resin were incubated with ${ }^{35}$ S-labeled Cdc20p and Cdh1p and washed. The bound proteins were run on SDS-polyacrylamide gels and analyzed for Cdc20p or Cdh1p by fluorography (Fig. 6 , top panels). ${ }^{35}$ S-labeled Cdc20p bound to MBPHsllp $\mathrm{p}^{667-872}$ and MBP-Hsllp $\mathrm{p}^{667-872 \mathrm{mkb}}$, but not to MBP

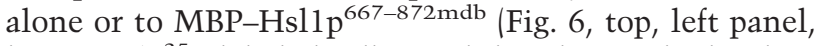
lanes 1-4). ${ }^{35}$ S-labeled Cdh1p exhibited a similar binding profile for the different forms of MBP-Hsllp ${ }^{667-872}$ (Fig. 6, top panels, cf. lanes 6-8 with lanes 2-4). Similar amounts of the recombinant MBP-Hsllp $\mathrm{p}^{667-872}$ proteins were present on the amylose beads, as visualized by Coomassie staining (Fig. 6, lower panels). Currently, we do not know why mutation of the KEN box has less of an

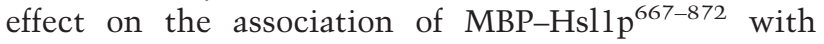
Cdh1p (see also below), than on that of full-length Hsllp with Cdh1p.

We used purified proteins to rule out the possibility that the interaction of Hsllp with these proteins was mediated by a core APC subunit or other protein from the reticulocyte lysate. We used purified Cdh1p-6xHis recombinant protein from insect cells (Jaspersen et al. 1999 ) in binding assays with MBP-Hsl1p ${ }^{667-872}$. Extracts from uninfected control cells or from cells infected with a baculovirus encoding Cdh1p-6xHis were incubated with Talon metal affinity resin (Clonetech) to purify Cdh1p-6xHis. A band corresponding to Cdh1p6xHis was observed (Fig. 7A, lane 7 arrow) in the sample derived from baculovirus-infected cells that migrated at the appropriate molecular weight and was absent in the uninfected cell control (Fig. 7A, cf. lanes 6 and 7). Extracts from E. coli cells expressing MBP, MBPHsllp ${ }^{667-872}$, MBP-Hsllp 667-872mdb $^{6}$ MBP-Hsllp ${ }^{667-872 m k b}$, or MBP-Hsllp $\mathrm{p}^{667-872 \mathrm{mdb} / \mathrm{mkb}}$ were prepared (Fig. 7A, lanes 1-5). The different E. coli extracts were incubated either with resin bound to Cdh1p-6xHis or with beads incubated with uninfected cell extracts. Beads were washed and bound proteins were examined by Coomassie staining of SDS-polyacrylamide gels (Fig. 7B). Protein bands corresponding to the MBP-Hsllp $\mathrm{p}^{667-872}$ fusion proteins were observed clearly in eluates from the Cdh1p-6xHis beads, but not with the uninfected cell bead eluates (Fig. 7B, cf. lanes 2-4 with lanes 6-8). MBPHsllp $\mathrm{p}^{667-872 \mathrm{mdb}}$ appeared to bind Cdhlp somewhat

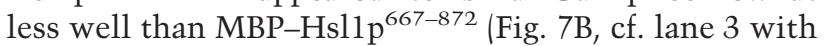
lane 2). The nonspecific binding of MBP to both of the resins (Fig. 7B, lanes 1 and 5 ) is likely due to the massive 


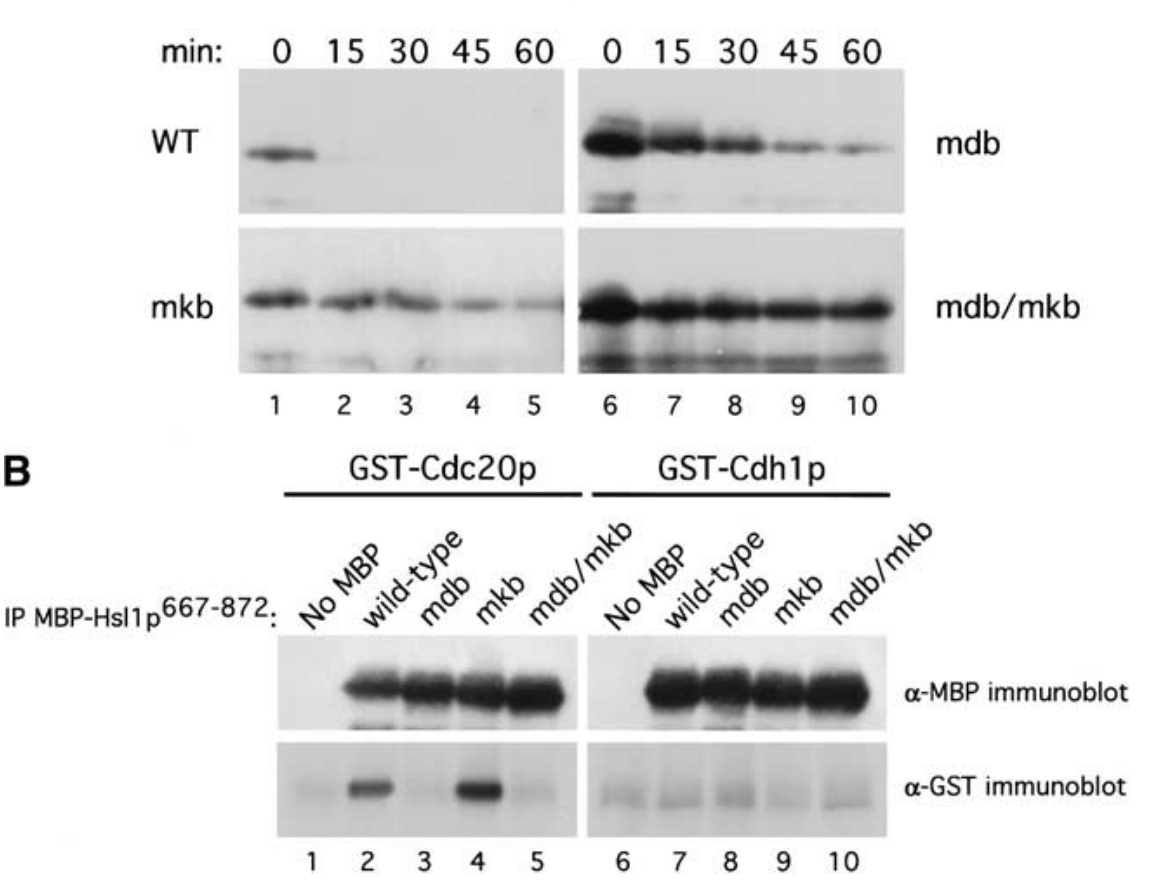

Figure 5. Degradation of MBP-Hsllp ${ }^{667-872}$ in $G_{1}$ requires intact $D$ box and KEN box motifs. (A) Cells were arrested in $\mathrm{G}_{1}$ with $\alpha$-factor and then induced to express WT, $\mathrm{mdb}, \mathrm{mkb}$ or $\mathrm{mdb} / \mathrm{mkb}$ isoforms of MBPHsllp $\mathrm{p}^{667-872}$ by the addition of galactose (strains YJB306, YJB326, YJB327 and YJB328, respectively). MBP-Hsl1p ${ }^{667-872}$ levels were monitored by immunoblot analysis with anti-MBP antibodies at the indicated times after glucose/cycloheximide addition. $(B) \mathrm{D}$ box-dependent binding of GST-Cdc20p to MBP-Hsllp ${ }^{667-872}$. MBP-Hsllp ${ }^{667-872}$ was immunoprecipitated with anti-MBP antibodies from extracts of cells expressing GST-Cdc20p and GST-Cdh1p. Precipitated proteins were analyzed for the presence of GST-Cdc20p and GST-Cdh1p by immunoblot analysis with anti-GST antibodies (lower panels) and for MBP-Hsl1p $\mathrm{p}^{667-872}$ fusion proteins by immunoblot analysis with anti-MBP antibodies (upper panels). (Lanes 1-10) Strains YJB221, YJB309, YJB338, YJB339, YJB340, YJB222, YJB310, YJB341, YJB342 and YJB343, respectively. amounts of MBP in the E. coli lysates (Fig. 7A, cf. lane 1 with lanes 2-5). Given the high stoichiometry of MBPHsllp-Cdh1p binding, it is unlikely that their association is mediated by a contaminant in the Cdh1p-6xHis preparation because these are all present at very low stoichiometries relative to $\mathrm{Cdh} 1 \mathrm{p}-6 \mathrm{xH}$ is and are also present in the preparation from uninfected cells (Fig. 7A lanes 6 and 7).

We improved the sensitivity of this assay to D box and KEN box mutations by diluting the E. coli lysates sufficiently (20-fold) that binding of MBP-Hsllp ${ }^{667-872}$ pro- teins began to decline. We also reduced the amount of MBP alone (by 320-fold) so that it was similar to the amount of the MBP-Hsl1p $\mathrm{p}^{667-872}$ fusion proteins used. By Coomassie staining we observed binding of MBPHsllp $\mathrm{p}^{667-872}$ and MBP-Hsllp $\mathrm{p}^{667-872 \mathrm{mkb}}$ to Cdhlp6xHis (Fig. 8A, lanes 2 and 4). A faint band corresponding to MBP-Hsllp ${ }^{667-872 m d b}$ was detected by Coomassie staining and confirmed by immunoblot analysis (Fig. $8 \mathrm{~A}, \mathrm{~B}$, lane 3). Mutation of both the $\mathrm{D}$ box and the KEN box abolished detectable binding to Cdh1p-6xHis completely (Fig. 8A,B, lane 5). MBP and the MBP-
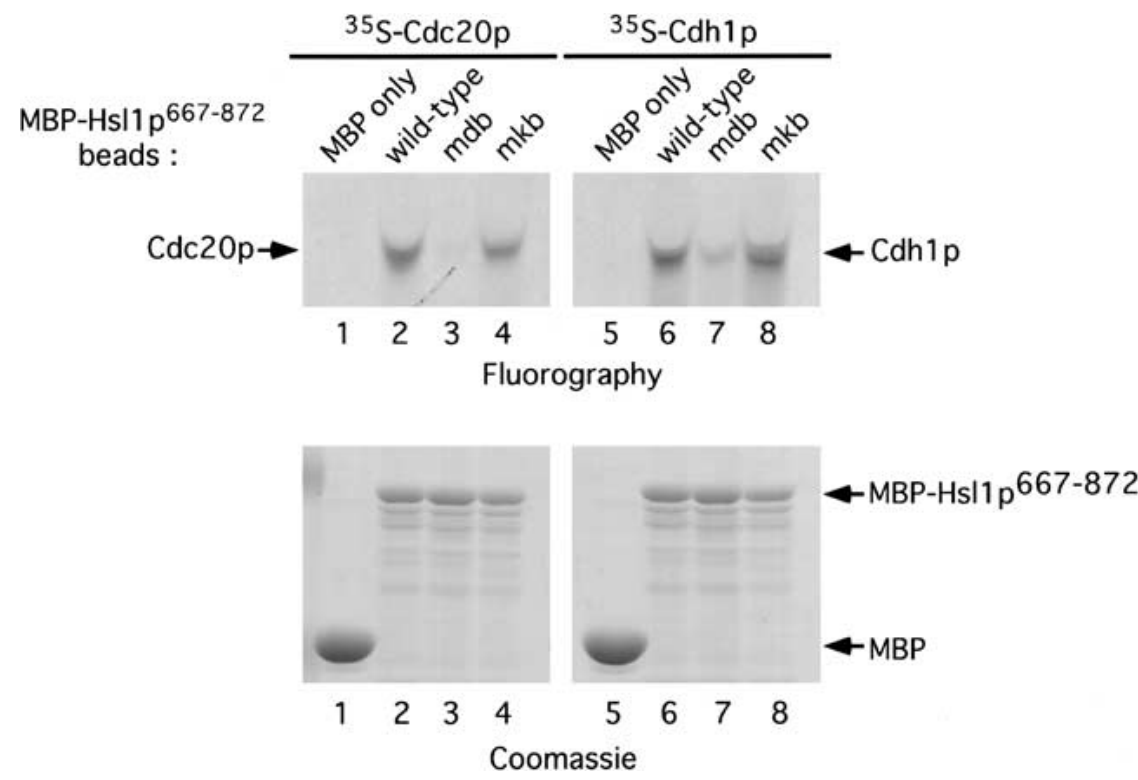

Figure 6. Cdc20p and Cdhlp translated in vitro can bind purified MBP-Hsl1p $\mathrm{p}^{667-872}$ in a $\mathrm{D}$ box-dependent fashion. E. coli expressed MBP or MBP-Hsl1p $\mathrm{p}^{667-872}$ proteins were purified on amylose resin and then mixed with $\left[{ }^{35} \mathrm{~S}\right]$ methionine-labeled Cdc20p or Cdh1p (see Materials and Methods). Proteins bound to the resin were run on SDS-PAGE and visualized by fluorography (upper panels). Similar amounts of the MBP-Hsl1p 667-872 $^{6 r o t e i n s ~ w e r e ~ p r e s e n t ~ o n ~}$ the amylose beads as visualized by Coomassie staining following SDS-PAGE (lower panels). 
Figure 7. Direct binding of Cdhlp to MBPHsllp $\mathrm{p}^{667-872}$. (A) Coomassie stained gels of starting materials used for the direct binding assays in $B$ and in Figure 8. (Left panel) $10 \mu \mathrm{L}$ of total E. coli extracts expressing MBP or the different forms of MBPHsl1p ${ }^{667-872}$. (Right panel) $25 \mu \mathrm{L}$ of cobalt resin from uninfected cell extracts and Cdh1p-6xHis baculovirus-infected $\mathrm{Sf} 9$ cell extracts. $(B)$ Cobalt resin was incubated with extracts from insect cells infected with Cdh1p-6xHis baculovirus (lanes1-4) or from uninfected cells (lanes 5-8). Resins were washed and then incubated with $1 \mathrm{~mL}$ of the indicated $E$. coli extracts containing MBP or one of the MBPHsl1p $\mathrm{p}^{667-872}$ fusion proteins and washed. Bound proteins were eluted with $150 \mathrm{mM}$ imidizole and visualized by Coomassie staining following SDS-PAGE.

Hsllp $\mathrm{p}^{667-872}$ proteins did not bind to the control uninfected cell resin (Fig. 8A,B, lanes 6-10).

Direct binding of Hsllp $\mathrm{p}^{667-872}$ to Cdc20p was tested using the diluted bacterial extracts expressing MBP or the MBP-Hsl1p $\mathrm{p}^{667-872}$ proteins and GST-Cdc20p expressed and purified from insect cells (Fig. 8C). Like Cdh1p-6xHis, GST-Cdc20p bound to MBP-Hsl1p ${ }^{667-872}$ and MBP-Hsllp ${ }^{667-872 m k b}$, but showed no detectable binding to MBP-Hsl1p ${ }^{667-872 \mathrm{mdb} / \mathrm{mkb}}$ (Fig. 8C, lanes 2, 4, and 5). Reduced but detectable binding to MBPHsllp $\mathrm{p}^{667-872 \mathrm{mdb}}$ was observed (Fig. 8C, cf. lanes 3 and 8). These results indicate that $\mathrm{MBP}-\mathrm{Hsl1p} \mathrm{p}^{667-872}$ binds Cdh1p-6xHis and GST-Cdc20p directly and that the interactions require intact $\mathrm{D}$ box and KEN box motifs within Hsllp.

\section{Discussion}

We found that Hsllp contains both a D box and a KEN box degradation motif, both of which are important for APC-mediated turnover with either $\mathrm{APC}^{\mathrm{Cdc} 20}$ or APC $^{\text {Cdh1 }}$. A 206-amino-acid segment $\left(H_{s l 1} p^{667-872}\right)$ containing these degradation signals was sufficient to promote APC-mediated degradation of an otherwise stable protein in yeast. Finally, this domain of Hsllp was able to interact directly with Cdh1p and Cdc20p, dependent on an intact D box and KEN box. The identification of a yeast protein with a functional KEN box indicates that this motif is conserved evolutionarily.
The $D$ box and the KEN box form a bipartite degradation signal in Hsl1p

Hsllp is a member of a growing subfamily of APC substrates that contain KEN boxes. The KEN box was first identified in human CDC20 and Nek2 and in mouse B99 as a motif essential for the Cdh1-dependent degradation of these proteins (Pfleger and Kirschner 2000). Subsequently, essential KEN boxes have been found in human CDC6 (Peterson et al. 2000), human securin (Zur and Brandeis 2001), Drosophila cyclin A (Jacobs et al. 2001), and now budding yeast Hsllp. In these four cases, a functional D box is located within 53 amino acids of the KEN box /counting from the lysine of the KEN box to the arginine of the D box). A simple database search of budding yeast sequences reveals 92 proteins containing matches to both a basic D box (RxxLxxxx(NDEQ)) and a basic KEN box (KENxxx(NDEQ)), in 32 of which the two motifs are separated by fewer than 100 amino acids. Although only some of these proteins will be authentic APC substrates, the exercise indicates that dual recognition may be a common theme (discussed in more detail below). It is interesting to note that Cut2p and Pds1p, the securin proteins in fission and budding yeast, respectively, each contain a potential KEN box within the first 15 amino acids of the protein, situated upstream of their characterized D boxes. This positioning is virtually identical to that of the characterized KEN box in human securin (Zur and Brandeis 2001), indicating that the positioning of these motifs is criti- 

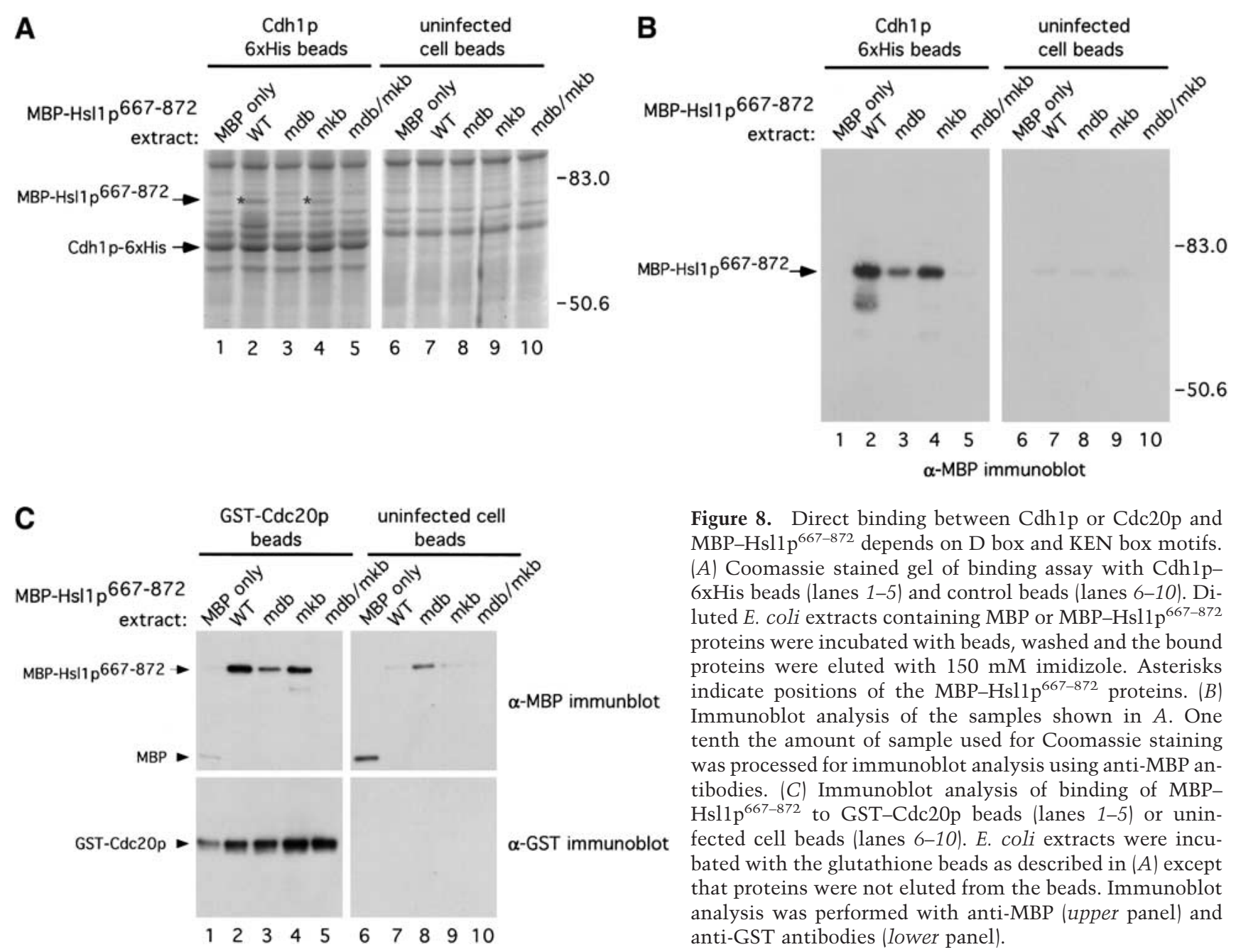

Figure 8. Direct binding between Cdh1p or Cdc20p and MBP-Hsl1p ${ }^{667-872}$ depends on D box and KEN box motifs. (A) Coomassie stained gel of binding assay with Cdh1p6xHis beads (lanes 1-5) and control beads (lanes 6-10). Diluted E. coli extracts containing MBP or MBP-Hsl1p ${ }^{667-872}$ proteins were incubated with beads, washed and the bound proteins were eluted with $150 \mathrm{mM}$ imidizole. Asterisks indicate positions of the MBP-Hsllp $\mathrm{p}^{667-872}$ proteins. $(B)$ Immunoblot analysis of the samples shown in $A$. One tenth the amount of sample used for Coomassie staining was processed for immunoblot analysis using anti-MBP antibodies. (C) Immunoblot analysis of binding of MBPHsllp ${ }^{667-872}$ to GST-Cdc20p beads (lanes 1-5) or uninfected cell beads (lanes 6-10). E. coli extracts were incubated with the glutathione beads as described in $(A)$ except that proteins were not eluted from the beads. Immunoblot analysis was performed with anti-MBP (upper panel) and anti-GST antibodies (lower panel).

cal, despite the low overall similarity between these proteins.

Both the D box and the KEN box are essential for efficient Hsllp degradation by both $\mathrm{APC}^{\mathrm{Cdc} 20}$ and APC $^{\text {Cdh1 } 1}$. The efficient degradation of Hsllp in $G_{1}$ cells containing only one form of the APC (either APC ${ }^{\text {Cdh1 }}$, Figs. 1 and 5, or $\mathrm{APC}^{\mathrm{Cdc} 20}$, Fig. 2) indicates that these signals are recognized in concert, not by parallel pathways. The ability of both $\mathrm{APC}^{\mathrm{Cdc} 20}$ and $\mathrm{APC}^{\mathrm{Cdh} 1}$ to recognize both motifs suggests that many proteins will be substrates for both forms of the APC, although at different times. For Hsllp it is likely that $\mathrm{APC}^{\mathrm{Cdc} 2 \mathrm{O}}$ initiates Hsllp degradation during mitosis, whereas any remaining Hsllp may be degraded by $\mathrm{APC}^{\mathrm{Cdh} 1}$ during mitotic exit and entry into $G_{1}$. In addition to temporal control, it is possible that differences in substrate specificity between these APC forms could arise from differences in affinity for particular degradation motifs within a substrate, or from weak interactions with other regions of the substrate.

The interplay between the D box and the KEN box is not as clear for the other characterized KEN box-containing proteins. Human CDC20 does not contain an obvious D box and is degraded solely by APC ${ }^{\text {Cdh } 1}$ (Pfleger and
Kirschner 2000). No D box was reported for either Nek2

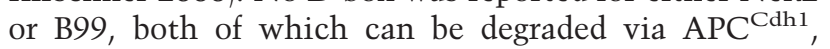
although it was not reported whether they can also be degraded via APC ${ }^{\mathrm{Cdc} 20}$ (Pfleger and Kirschner 2000). These studies led to the suggestion that the KEN box was required for recognition by $\mathrm{APC}^{\mathrm{Cdh} 1}$ but not $\mathrm{APC}^{\mathrm{Cdc} 20}$. Intriguingly, potential D boxes have been identified in both Nek2 and B99 (C. Pfleger and M. Kirschner, pers. comm.). In human CDC6, mutation of either the D box or the KEN box could stabilize CDC6 partially, whereas the double mutant was stabilized fully (Peterson et al. 2000). For Drosophila cyclin A, both motifs must be intact for full instability (Jacobs et al. 2001). In contrast, either motif was capable of destabilizing human securin (Zur and Brandeis 2001). Human CDC6, Drosophila cyclin A, and human securin were reported to be degraded by $\mathrm{APC}^{\mathrm{Cdh} 1}{ }, \mathrm{APC}^{\mathrm{Cdc} 20}$, and either $\mathrm{APC}^{\mathrm{Cdh} 1}$ or APC ${ }^{\mathrm{Cd} 20 \mathrm{p}}$, respectively (Peterson et al. 2000; Jacobs et al. 2001; Zur and Brandeis 2001). In these studies, however, it was not tested whether human CDC6 and Drosophila cyclin A could also be degraded via $\mathrm{APC}^{\mathrm{Cdc} 20}$ and $\mathrm{APC}^{\mathrm{Cdh} 1}$, respectively (Peterson et al. 2000; Jacobs et al. 2001). Taken together, these findings suggest that some proteins require a bipartite KEN 
box/D box signal for APC-mediated proteolysis and that both $\mathrm{APC}^{\mathrm{Cdh} 1}$ and $\mathrm{APC}^{\mathrm{Cdc} 20}$ can recognize the KEN box degradation signal. Other substrates seem to have both motifs, though the roles of each have not yet been tested. Finally, it is possible that still other APC substrates that appear to lack one of these motifs actually have highly degenerate ones that are not recognizable by crude primary sequence analysis (see below).

\section{Direct binding of APC substrates to Cdc20 and Cdh1}

Hsllp binds directly to Cdc20p and Cdh1p and these interactions are mediated by the D box and KEN box within Hsllp. This finding simultaneously identifies a biochemical role for these degradation motifs and establishes Cdh1p and Cdc20p as substrate targeting proteins for the APC. The simplest model would be that these proteins bind directly to the degradation motifs within the APC substrate. However, it remains a formal possibility that intact D box and KEN box signals are not the actual sites of Cdc20 and Cdh1 binding but rather influence protein conformation at a distant site(s) that interacts with these proteins.

The $\mathrm{D}$ box was most important for the interaction of full-length Hsllp with Cdc20p, whereas the KEN box was more important for the interaction with Cdhlp. Currently, it is unclear why the KEN box was critical for Cdhlp-binding to full-length Hsllp whereas the D box was important for Cdhlp-binding to MBP-Hsllp $\mathrm{p}^{667-872}$. It is possible that other sequences in the full-length protein interfere with the ability of Cdhlp to recognize the D box. Nevertheless, elimination of both motifs was required to disrupt the interaction between MBPHsllp $\mathrm{p}^{667-872}$ and Cdhlp in vitro. Due to the previous absence of demonstrable direct binding to APC substrates, Cdh1 and Cdc20 have been widely viewed as APC activators with one or more of the APC core subunits serving as a substrate receptor. Although we cannot exclude an additional role for Cdc20p and Cdh1p in APC activation, our results establish that one essential function of these proteins is to bind Hsllp. In agreement with our findings, a direct interaction between the $\mathrm{N}$ termini of hCDC20 and hCDH1 with several APC substrates has been shown (Pfleger et al. 2001).

Given the conservation of the APC ubiquitin ligase and of $\mathrm{D}$ boxes and KEN boxes, we suggest that Cdc20 and Cdh1 proteins serve to target all substrates to the APC. For many substrates, this interaction may be too weak to survive coimmunoprecipitation regimens. Nonetheless, even a transient interaction, as in other enzyme-substrate interactions, may suffice for presentation to the APC. Hsllp was identified via its two-hybrid interaction with Cdc20p (Burton and Solomon 2000) and therefore may represent the high-affinity end of a spectrum of interactions of substrates with Cdc20p and Cdhlp. Although direct binding of APC substrates has not been reported previously, the different substrate specificities of APC ${ }^{\mathrm{Cdc} 20}$ and APC ${ }^{\mathrm{Cdh} 1}$ (Schwab et al. 1997; Visintin et al. 1997; Fang et al. 1998a; Shirayama et al. 1998; Pfleger and Kirschner 2000), plus the different effects of a D box mutation in full-length Hsllp on association with Cdc20p and Cdh1p (Burton and Solomon 2000), had provided indirect evidence for a targeting function for Cdc20 and Cdh1.

\section{A model for substrate presentation by Cdc20 and Cdh1}

An important aspect of our findings is that substrate binding to Cdc20p and Cdh1p is not necessarily sufficient for efficient degradation of that substrate. For example, mutation of the D box or the KEN box of Hsllp compromised its degradation severely, but still allowed strong binding to Cdhlp or Cdc20p, respectively. Similarly, mutation of the D box stabilizes Clb2p (Amon et al. 1994; Irniger et al. 1995), but had little effect on its binding to Cdc20p or Cdh1p (Fig. 3). Although a KEN box was sufficient for Hsllp to bind to Cdhlp in vivo, a D box was still needed for what can be termed the "presentation" of Hsllp to the APC in an orientation that leads to efficient degradation. Our results suggest that both Cdc20p and Cdh1p need to bind both degradation motifs in order to present Hsllp to the APC properly. A prediction of this model is that Cdc20p and Cdh1p each have two binding sites, one for a D box and one for a KEN box.

Do other APC substrates interact with Cdc20 and/or Cdh1 via both a D box and a KEN box? The simple answer would seem to be no as only a minority of APC substrates contain both motifs. Interestingly, the two motifs are usually very close together, being separated by 25 to 53 amino acids (from the start of one motif to the start of the second) in the four characterized proteins with both motifs (human CDC6, human securin, Drosophila cyclin A, and yeast Hsllp). A large number of potential substrates seem to have both motifs close together (see above). This striking juxtaposition is consistent with simultaneous interaction of the two degradation motifs with two binding pockets on Cdc20p or Cdh1p. In a number of APC substrates, only one motif (usually a D box) has been identified and found necessary for degradation. Perhaps in these cases binding via just one motif can present the substrate properly to the APC. Dual motif binding may be more efficient, but one motif can suffice. Indeed, single mutations in Hsllp reduced degradation severely, but did not eliminate it. An alternative possibility is that both the D box- and the KEN box-binding regions of Cdc2 0 and $\mathrm{Cdh} 1$ must be engaged for efficient substrate presentation. In such a model, substrates that contain only one discernable degradation motif still must contain sequences that are compatible with the second binding pocket of Cdc20 and/or Cdh1 in order to be presented for ubiquitination by the APC. The main binding energy for the interaction would come from the obvious degradation motif, whereas important positional information could come from a weak interaction provided by a highly degenerate motif. Structural insights will be required to address these issues in further detail. 


\section{Materials and methods}

Yeast strains and plasmid constructions

All yeast strains are derivatives of W303 lade2-1 trp1-1 leu23,112 his3-11,15 ura3-1 can1-100); their relevant genotypes are listed in Table 1. Plasmids are denoted by brackets. Yeast transformations were performed using published methods (Gietz et al. 1995). All PCR products were sequenced to confirm that no extraneous mutations were introduced. Underlined residues in oligonucleotides indicate introduced restriction sites or nucleotide changes, as appropriate. All mutagenesis was performed by Quikchange (Stratagene). Yeast media (YPD and complete minimal [CM]) were prepared as described (Ausubel et al. 1995).

The GAL-HSL1-HA-YIplac128 and GAL-HSL1 ${ }^{m d b}-H A-$ YIplac128 constructs were described previously (Burton and Solomon 2000). GAL-HSL1 ${ }^{\mathrm{mkb}}-H A-Y I p l a c 128$ and $G A L-$ $H S L 1^{\mathrm{mdb} / \mathrm{mkb}}-H A$-YIplac128 were made from $G A L-H S L 1-H A-$ YIplac128 or GAL-HSL1 ${ }^{\text {mdb }}-H A-Y I p l a c 128$, respectively, using oligonucleotides MSO880 (5'-CG/ATC/TCT/GGG/GTG/TCT/

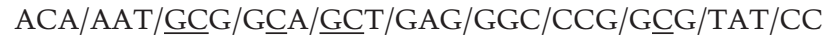
A/ACC/AAA/ATT/GAG-3') and MSO881 (5'-CTC/AAT/TTT/ GGT/TGG/ATA/CGC/CGG/GCC/CTC/AGC/TEC/CGC/AT T/TGT/AGA/CAC/CCC/AGA/GAT/CG-3'). The nucleotide changes result in the mutagenesis of the KEN box motif (bold indicates mutated amino acids) $\mathbf{K}^{775} \mathbf{E}^{776} \mathbf{N}^{777} \mathbf{X X X E}^{781}$ within Hsllp to $\mathbf{A}^{775} \mathbf{A}^{776} \mathbf{A}^{777} \mathbf{X X X A}^{781}$.

GAL-CLB2-HA-YIplac128 was made by PCR amplification of CLB2 using MSO899 (5' -CCC/GGA/TCC/ATG/TCC/AAC/ CCA/ATA/GAA/AAC/ACA/G-3') and MSO898 ( 5'-CCC/ GTC/GAC/TTC/ATG/CAA/GGT/CAT/TAT/ATC/ATA/GC C-3'), digesting with BamHI and SalI and ligating to $G A L-$ YIplac128-HA cut with the same enzymes. GAL-CLB2 ${ }^{m d b}$ $H A-Y I p l a c 128$ was created by mutagenesis of $G A L-C L B 2-H A-$ YIplac128 using oligonucleotides MSO891 (5'-GG/TTT/TTG) AGG/AAT/GTA/CAA/GCT/TTG/GCC/GCA/AAC/AAT/GT A/ACA/GCT/ACG/ACA/TTT/CAA/AAG/AGT/AAT/GCG-3') and MSO892 (5'-CGC/ATT/ACT/CTT/TTG/AAA/TGT/CGT/

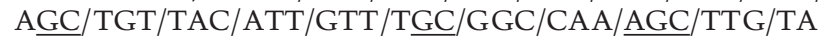
C/ATT/CCT/CAA/AAA/CC-3'). Nucleotide changes result in the mutagenesis of the $\mathbf{R}^{25} \mathrm{XXL}^{28} \mathrm{XXXXN}^{33}$ destruction box within Clb2p to $\mathbf{A}^{25} \mathrm{XXA}^{28} \mathrm{XXXXA}^{33}$.

To make maltose-binding protein (MBP)-HSL1 fusions in yeast, the $G A L-M B P-Y E p l a c 181$ vector was constructed. The malE gene and MCS from pMAL-c2 (New England Biolabs) was amplified using MSO910 (5'-CCC/GAT/ATC/ATG/AAA/ ATC/GAA/GAA/GGT/AAA/CTG/G-3') and MSO911 (5'-CCC/ AAG/CTT/GCC/TGC/AGG/TCG/ACT/CTA/GAG/G-3'), cut with EcoRV and HindIII, and ligated to pEG-[KT] (Mitchell et al. 1993) that was cut with SacI, end-filled with T4 DNA polymerase, and then cut with HindIII. This construct was then digested with ScaI and HindIII to isolate a GAL-malE-containing fragment with the MCS of pMAL-c2. This fragment was ligated to YEplac181 that had been cut with EcoRI, blunted, and then cut with HindIII to yield GAL-MBP-YEplac181. Various fragments of HSL1 (see below) were amplified by PCR, cut with BamHI and SalI, and ligated to GAL-MBP-YEplac181 cut with the same enzymes to yield constructs encoding MBP-Hsllp fusions for expression in yeast cells. GAL-MBP-HSL1 $1^{667-872}$-YEplac181 and mutant derivatives were constructed by PCR from GALHSL1-HA-YIplac128 and its mutant versions using MSO919 (5'-CCC/GGA/TCC/ATG/CAA/AAC/TCG/GCT/TCA/AAG/ TCC-3') and MSO920 (5'-CCC/GTC/GAC/CTG/AAT/AGG/ TTT/GAG/TGG/TG-3'). The following GAL-MBP-HSL1 derivatives were made by $\mathrm{PCR}$ with the indicated oligonucleotides: GAL-MBP-HSL1 167-837-YEplac181, MSO919 and MSO940 (5'-CCC/丽C/GAC/TGA/GTT/CGT/GAT/ATC/
TGA/AAG-3'); GAL-MBP-HSL1 101-872_YEplac181, MSO942 (5'-CCC/GGA/TCC/ATG/AAG/AAA/CCA/GCA/TCC/GAA/ AAT/GTG-3') and MSO920; GAL-MBP-HSL1 101-837YEPlac181, MSO942 and MSO940; GAL-MBP-HSL1 $1^{740-872}$ YEplac181, MSO943 (5'-CCC/GGA/TCC/ATG/GAA/GAG/ GAA/GAG/GAC/AAT/G-3') and MSO920; GAL-MBPHSL1 140-837-YEPlac181, MSO943 and MSO940; GAL-MBPHSL1 164-872_YEplac181, MS0918 (5'-CCC/GGA/TCC/ATG/ GAC/ACT/TTT/ACG/ATC/TCT/GGG-3') and MSO920.

HSL $1^{667-872}$-pMAL-c2 and mutant derivatives were constructed for expression of MBP-Hsllp $\mathrm{p}^{667-872}$ in E. coli by cutting the appropriate $G A L-M B P-H S L 1^{667-872}-$ YEplac181 plasmids with BamHI and SalI to isolate the DNA fragment containing $H S L 1^{667-872}$, which was then ligated to pMAL-c2 cut with the same enzymes.

GAL-HSL1-HA-pRS303 was described previously (Burton and Solomon 2000). GAL-HSL1 $1^{m d b}-H A-p R S 303$ and GAL$H S L 1^{m k b}-H A-$ pRS303 were made by cutting the corresponding constructs in YIplac128 with HindIII, blunting the ends with Klenow (New England Biolabs), digesting with BamHI, isolating the HSL1-HA isoforms, and ligating into pRS303 cut with XbaI, end-filled with Klenow, and then cut with BamHI.

pEG-[KT]-CDC20 and pEG-[KT]-CDH1 were described previously (Burton and Solomon 2000). GAL-CDC20-mycYIplac211 was constructed by isolating CDC20 from pEG-[KT]CDC20 by cutting with SmaI and SalI. The CDC2O fragment was then ligated to YIplac211-myc, cut with BamHI, end-filled with Klenow, and then cut with SaII. CDC20- and CDH1-Bluescript constructs used for in vitro translations (see below) were obtained by PCR using pEG-[KT]-CDC2O and pEG-[KT]-CDH1 as PCR templates. For CDC20, oligonucleotides MSO954 (5'CCC/ATG/GCA/ATG/CCA/GAA/AGC/TCT/AGA/G-3') and MSO955 (5'-CCC/CTC/GAG/CCT/GAT/CAA/ATA/TTG/ GCT/GG-3') were used, and for CDH1, oligonucleotides MSO956 (5'-CCC/ATG/GCA/ATG/TCC/ACA/AAC/CTG/ $\left.\mathrm{AAC} / \mathrm{CC}-3^{\prime}\right)$ and MSO957 (5'-CCC/CTC/GAG/ACG/TAT/ TTG/ATT/AAA/TGC/GTC-3') were used. The resulting PCR products were cut with $\mathrm{NcoI}$ and $\mathrm{XhoI}$ and ligated to Bluescript II KS- (Stratagene) cut with the same enzymes. The GSTCDC20 baculovirus construct was made by subcloning CDC20 into the pVT4 vector (a kind gift from Vasiliki Tsakraklides, Yale University, New Haven, CT). pVT4 was constructed by PCR amplification of GST using MSO810 (5'-GGG/ GGA/TCC/ATG/TCC/CCT/ATA/CTA/GGT/TAT-3') and MSO811 (5'-G/GGC/GGA/CCG/CTT/AAG/ATC/GAT/TCC/ CGG/GCC/CAT/GGA/GCC/ACG/CGG/AAC/CAG/GGA/ GGA/GGA/TTT/TGG/AGG/ATG/GTC/GCC/ACC-3'), digestion with BamHI and RsrII, and ligation to pFASTBAC1 /GIBCO BRL) cut with the same enzymes. The complete CDC20 coding region was cloned into pVT4 by a blunt-end ligation using the AfIII site in pVT4. The CDH1-6xHis baculoviral construct (Jaspersen et al. 1999) was a kind gift from Dr. David Morgan (University of California, San Francisco).

\section{Hsl1p half-life studies}

Half-life experiments for Hsllp-HA and the various MBP-Hsllp fusions were essentially as described previously (Burton and Solomon 2000). Briefly, cells were arrested in $\mathrm{G}_{1}$ with $\alpha$-factor (100 ng/mL), induced to express Hsllp-HA or MBP-Hsllp by the addition of galactose $(2 \%)$, and shifted to $37^{\circ} \mathrm{C}$ to inactivate the APC where appropriate. Expression was terminated by the addition of glucose $(2 \%)$ and cycloheximide $(0.5 \mathrm{mg} / \mathrm{mL})$. For half-life studies in $c d h 1 \Delta c d c 28-13$ cells expressing Hsllp-HA isoforms, a $\mathrm{G}_{1}$ arrest was achieved by shifting to $37^{\circ} \mathrm{C}$ for $3 \mathrm{~h}$ and then treating cells as above except that cells were kept at 
Table 1. Yeast strains used in this study

\begin{tabular}{|c|c|c|}
\hline Strain & Genotype & Reference \\
\hline YJB14 & MATa bar1s & Burton and Solomon 2000 \\
\hline YJB115 & MATa bar1 $\Delta:: U R A 3$ cdc23-1 & Burton and Solomon 2000 \\
\hline YJB123 & MATa bar1 $G A L-H S L 1-H A:: T R P 1$ & Burton and Solomon 2000 \\
\hline YJB125 & MATa bar1 $::: U R A 3$ cdc23-1 GAL-HSL1-HA::TRP1 & Burton and Solomon 2000 \\
\hline YJB156 & YJB123 [pEG-KT-CDC20] & Burton and Solomon 2000 \\
\hline YJB218 & YJB123 [pEG-KT-CDH1] & Burton and Solomon 2000 \\
\hline YJB221 & YJB14 [pEG-KT-CDC20] & Burton and Solomon 2000 \\
\hline YJB222 & YJB14 [pEG-KT-CDH1] & Burton and Solomon 2000 \\
\hline YJB229 & MATa bar1 GAL-HSL1 $^{\mathrm{mdb}}-H A:: L E U 2$ & Burton and Solomon 2000 \\
\hline YJB230 & YJB229 [pEG-KT-CDC20] & Burton and Solomon 2000 \\
\hline YJB231 & YJB229 [pEG-KT-CDH1] & Burton and Solomon 2000 \\
\hline YJB257 & MATa bar1 GAL-HSL1 $^{\mathrm{mkb}}-H A:: L E U 2$ & This study \\
\hline YJB258 & 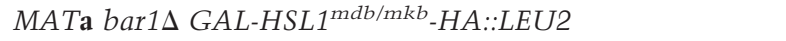 & This study \\
\hline YJB259 & YJB257 [pEG-KT-CDC20] & This study \\
\hline YJB260 & YJB258 [pEG-KT-CDC20] & This study \\
\hline YJB261 & YJB257 [pEG-KT-CDH1] & This study \\
\hline YJB262 & YJB258 [pEG-KT-CDH1] & This study \\
\hline YJB265 & MATa bar1 $:: U R A 3$ cdc23-1 GAL-HSL1 $1^{m d b / m k b}-H A:: L E U 2$ & This study \\
\hline YJB266 & MATa bar1 GAL-HSL1-HA::LEU2 & This study \\
\hline YJB270 & MATa bar1 $::: U R A 3$ cdc23-1 GAL-HSL1 ${ }^{\text {mdb }}-H A:: L E U 2$ & This study \\
\hline YJB271 & MATa bar1s::URA3 cdc23-1 GAL-HSL1 ${ }^{m k b}-H A:: L E U 2$ & This study \\
\hline YJB272 & MATa bar1s::URA3 cdc23-1 GAL-HSL1 ${ }^{m d b / m k b}-H A:: L E U 2$ & This study \\
\hline YJB273 & MATa bar1 $\triangle$ GAL-CLB2-HA::LEU2 & This study \\
\hline YJB274 & 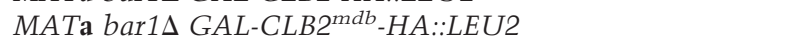 & This study \\
\hline YJB275 & YJB273 [pEG-KT-CDC20] & This study \\
\hline YJB276 & YJB274 [pEG-KT-CDC20] & This study \\
\hline YJB277 & YJB273 [pEG-KT-CDH1] & This study \\
\hline YJB278 & YJB274 [pEG-KT-CDH1] & This study \\
\hline YJB306 & YJB14 [GAL-MBP-HSL1 $1^{667-872}$-YEplac181] & This study \\
\hline YJB307 & YJB14 [GAL-MBP-HSL1 164-872-YEplac181] & This study \\
\hline YJB308 & YJB115 [GAL-MBP-HSL1 $1^{667-872}$-YEplac181] & This study \\
\hline YJB309 & YJB306 [pEG-KT-CDC20] & This study \\
\hline YJB310 & YJB306 [pEG-KT-CDH1] & This study \\
\hline YJB311 & YJB115 [GAL-MBP-HSL1 ${ }^{764-872}$-YEplac181] & This study \\
\hline YJB320 & YJB14 [GAL-MBP-HSL1 $1^{667-837}$-YEplac181] & This study \\
\hline YJB321 & YJB14 [GAL-MBP-HSL1 101-872-YEplac181] & This study \\
\hline YJB322 & YJB14 [GAL-MBP-HSL1 ${ }^{740-872-Y E p l a c 181]}$ & This study \\
\hline YJB326 & YJB14 [GAL-MBP-HSL1 ${ }^{\text {mdb667-872-YEplac181] }}$ & This study \\
\hline YJB327 & YJB14 [GAL-MBP-HSL1 ${ }^{\text {mkb667-872-YEplac181] }}$ & This study \\
\hline YJB328 & YJB14 [GAL-MBP-HSL1 ${ }^{m d b / m k b 667-872}$-YEplac181] & This study \\
\hline YJB329 & YJB14 [GAL-MBP-HSL1 $1^{701-837}$-YEplac181] & This study \\
\hline YJB330 & YJB14 [GAL-MBP-HSL1 ${ }^{740-837}$-YEplac181] & This study \\
\hline YJB331 & YJB115 [GAL-MBP-HSL1 $1^{667-837}$-YEplac181] & This study \\
\hline YJB332 & YJB115 [GAL-MBP-HSL1 ${ }^{740-872}$-YEplac181] & This study \\
\hline YJB335 & YJB115 [GAL-MBP-HSL1 $1^{701-872}$-YEplac181] & This study \\
\hline YJB336 & YJB115 [GAL-MBP-HSL1 $1^{701-837}$-YEplac181] & This study \\
\hline YJB337 & YJB115 [GAL-MBP-HSL1 ${ }^{740-837}$-YEplac181] & This study \\
\hline YJB338 & YJB326 [pEG-KT-CDC20] & This study \\
\hline YJB339 & YJB327 [pEG-KT-CDC20] & This study \\
\hline YJB340 & YJB328 [pEG-KT-CDC20] & This study \\
\hline YJB341 & YJB326 [pEG-KT-CDH1] & This study \\
\hline YJB342 & YJB327 [pEG-KT-CDH1] & This study \\
\hline YJB343 & YJB328 [pEG-KT-CDH1] & This study \\
\hline YJB366 & W303a $c d c 28-13: T R P 1 ~ c d h 1 \Delta:: L E U 2$ GAL-HSL1-HA::HIS3 & This study \\
\hline YJB367 & YJB366 GAL-CDC20-myc::URA3 & This study \\
\hline YJB368 & W303a $c d c 28-13:: T R P 1$ cdh1A::LEU2 & This study \\
\hline YJB377 & YJB368 GAL-HSL1 ${ }^{m d b}-H A:: H I S 3$ & This study \\
\hline YJB387 & YJB377 GAL-CDC20-myc::URA3 & This study \\
\hline YJB379 & YJB368 GAL-HSL1 ${ }^{m k b}-H A:: H I S 3$ & This study \\
\hline YJB380 & YJB379 GAL-CDC20-myc::URA3 & This study \\
\hline
\end{tabular}


$37^{\circ} \mathrm{C}$ for the remainder of the experiment. Levels of protein were monitored by immunoblot analysis as described previously (Burton and Solomon 2000), using either rabbit anti-HA antibodies (50 ng/mL; Santa Cruz) or anti-MBP antibodies $(0.36$ $\mu \mathrm{g} / \mathrm{mL}$ ). Quantitative immunoblot analysis was performed on scanned autoradiographs using the program NIH Image 1.62 (developed at the U.S. National Institutes of Health and available on the Internet at http://rsb.info.nih.gov/nih-image//. Experimental samples and serial dilutions of Hsllp-HA from the same autoradiograph were scanned and assigned arbitrary units based on the dilution standard. Plots of wild-type Hsllp-HA are in arbitrary units, whereas the plots for Hsllp ${ }^{\text {mdb }}-\mathrm{HA}$ and Hsllp ${ }^{\text {mkb }}$-HA represent the ratios of Hsllp levels with and without Cdc20-myc expression to adjust for Cdc20p independent degradation of these proteins. Samples for FACS were prepared as described previously (Burton and Solomon 2000).

\section{Protein extract preparation}

Protein extracts for Hsllp half-life studies using full-length Hsllp-HA were prepared as described previously (Burton and Solomon 2000). For MBP-Hsllp fusions, extracts were prepared by bead-beating for $4 \mathrm{~min}$ in $1 \times$ sample buffer (SB; $16.6 \%$ SDS, $26 \%$ glycerol, $262 \mathrm{mM}$ Tris base, $150 \mathrm{mM} \mathrm{DTT}$ ) and boiling for $10 \mathrm{~min}$. Samples were spun for $5 \mathrm{~min}$ in a microcentrifuge and the supernatants were centrifuged for $10 \mathrm{~min}$ at 70,000 rpm at $15^{\circ} \mathrm{C}$ in a Beckman Optima ultracentrifuge in a TLA-100.2 rotor.

\section{Coimmunoprecipitation analysis}

For coexpression of wild-type, $\mathrm{mdb}, \mathrm{mkb}$, or $\mathrm{mdb} / \mathrm{mkb}$ forms of full-length Hsllp-HA with either GST-Cdc20p or GST-Cdh1p, cells were grown overnight in $100 \mathrm{~mL}$ of CM-Ura raffinose $(4 \%)$ to an $\mathrm{OD}_{600}$ of $0.35-0.40$. Galactose $(4 \%)$ was added for $6 \mathrm{~h}$ at $30^{\circ} \mathrm{C}$ to induce the expression of Hsllp-HA. Analysis of MBPHsllp fusions, coexpressed with GST-Cdc20p or GST-Cdh1p was as described above, except that CM-Ura-Leu medium was used. Extract preparation and immunoprecipitations were performed as described previously (Burton and Solomon 2000), except that anti-MBP antibodies $(18 \mu \mathrm{g})$ were used for immunoprecipitating MBP-Hsllp fusions.

\section{In vitro binding assays}

Recombinant MBP or MBP-Hsl1p $\mathrm{p}^{667-872}$ isoforms were produced by induction in E. coli with $0.3 \mathrm{mM}$ IPTG (Sigma) for $2 \mathrm{~h}$ at $37^{\circ} \mathrm{C}$ at an $\mathrm{OD}_{600}=0.5$. Cells were pelleted and then disrupted in Lysis buffer (20 mM Tris- $\mathrm{HCl}$ at $\mathrm{pH} 7.5,200 \mathrm{mM}$ $\mathrm{NaCl}$ ) containing protease inhibitors (1 mM PMSF, $10 \mu \mathrm{g}$ each leupeptin, chymostatin, and pepstatin [Chemicon]) by sonication for three times $1 \mathrm{~min}$ on ice with a 5 min rest between pulses (setting 5, Branson sonifier 450). Lysates were clarified by centrifugation at $10,000 \mathrm{rpm}$ for $30 \mathrm{~min}$ in an SA600 rotor (Sorvall) at $4^{\circ} \mathrm{C}$. Lysates were used either directly or diluted 20 -fold for MBP-Hsllp ${ }^{667-872}$ isoforms or 320-fold for MBP for use in binding assays using Cdh1p-6xHis bound to cobalt resin (Talon resin, Clonetech) or GST-Cdc20p bound to glutathione resin (Sigma; see below). For binding assays using in vitro translated ${ }^{35} \mathrm{~S}$-Cdc20p or ${ }^{35} \mathrm{~S}$-Cdh1p (see below), lysates were prepared as above except that the Lysis buffer also contained $1 \mathrm{mM}$ EDTA. MBP and MBP-Hsl1p $\mathrm{p}^{667-872}$ isoforms were purified from the $E$. coli lysates by incubation with amylose resin (New England Biolabs) for $2 \mathrm{~h}$ and washed three times with Wash buffer (20 $\mathrm{mM}$ Tris- $\mathrm{HCl}$ at $\mathrm{pH} 7.5,500 \mathrm{mM} \mathrm{NaCl}, 1 \mathrm{mM}$ EDTA). A final wash was performed in Lysis buffer with $1 \mathrm{mM}$ EDTA.
CDC20- and CDH1-Bluescript plasmids were translated in vitro using the $\mathrm{TNT}^{\circledR} \mathrm{T} 7$-coupled reticulocyte lysate system (Promega) for $3 \mathrm{~h}$ at $30^{\circ} \mathrm{C}$. Proteins were labeled using $0.4 \mu \mathrm{Ci}$ / $\mu \mathrm{L}\left[{ }^{35} \mathrm{~S}\right]$ methionine (NEN) in the reaction. $10 \mu \mathrm{L}$ of the above reaction was incubated with $10 \mu \mathrm{L}$ of amylose resin containing bound MBP or MBP-Hsl1p $\mathrm{p}^{667-872}$ isoforms (see above) in $1 \mathrm{~mL}$ of Lysis buffer plus $1 \mathrm{mM}$ EDTA for $2 \mathrm{~h}$ at $4^{\circ} \mathrm{C}$ with rotation. Beads were then washed three times in $1 \mathrm{~mL}$ Wash buffer and samples were run on SDS-PAGE and processed for fluorography.

Cdh1p-6xHis and GST-Cdc20p baculoviruses were used to infect $10^{8}$ Sf9 insect cells at a multiplicity of infection of 5 for $48 \mathrm{~h}$. Infected and uninfected cells were pelleted at $500 \mathrm{~g}$ for 5 min at $4^{\circ} \mathrm{C}$, frozen in liquid nitrogen, and stored at $-80^{\circ} \mathrm{C}$ for future use. Cells were lysed in $15 \mathrm{~mL}$ Lysis buffer as described (Fisher et al. 1995). Lysates were clarified by ultracentrifugation at $40,000 \mathrm{rpm}$ for $30 \mathrm{~min}$ at $4^{\circ} \mathrm{C}$ in a $60 \mathrm{Ti}$ rotor (Beckman). Lysates were then incubated with either $500 \mu \mathrm{L}$ of Talon cobalt resin (50\% slurry, Clonetech) or $400 \mu \mathrm{L}$ glutathione agarose $\left(50 \%\right.$ slurry, Sigma) for $1.5 \mathrm{~h}$ at $4^{\circ} \mathrm{C}$ with rotation. Talon beads were washed three times with $5 \mathrm{~mL}$ Buffer D $(50 \mathrm{mM}$ sodium phosphate, $300 \mathrm{mM} \mathrm{NaCl}, 10 \%$ glycerol at $\mathrm{pH} 7.8$ ) plus $1 \mathrm{mM}$ DTT and $10 \mathrm{mM}$ imidizole and then transferred to a $1.7-\mathrm{mL}$ tube in Buffer D plus $1 \mathrm{mM}$ DTT. Beads were pelleted and resuspended in $250 \mu \mathrm{L}$ of Buffer D plus $1 \mathrm{mM}$ DTT. Glutathione beads were washed three times with $5 \mathrm{~mL}$ of wash buffer (10 $\mathrm{mM}$ sodium phosphate at $\mathrm{pH} 7.5,500 \mathrm{mM} \mathrm{NaCl}, 1 \%$ Triton $\mathrm{X}-100)$ and once with $1 \mathrm{~mL} 1 \times$ PBS buffer $(10 \mathrm{mM}$ sodium phosphate at $\mathrm{pH} 7.5,150 \mathrm{mM} \mathrm{NaCl}$ ). Beads were transferred to a $1.7-\mathrm{mL}$ tube, pelleted, and resuspended in $200 \mu \mathrm{L}$ of $1 \times$ PBS. Fifty microliters of either bead slurry were then incubated with $1 \mathrm{~mL}$ of $E$. coli extract expressing MBP or MBP-Hsllp $667-872$ isoforms for $2 \mathrm{~h}$ at $4^{\circ} \mathrm{C}$ with rotation. Beads were pelleted, washed three times in $1 \mathrm{~mL}$ immunoprecipitation buffer $(50$ $\mathrm{mM}$ potassium HEPES at $\mathrm{pH} 7.6,1 \mathrm{mM} \mathrm{MgCl} 2,0.1 \%$ Tween-20, $10 \%$ glycerol), and then either eluted with $30 \mu \mathrm{L}$ of Buffer D plus $1 \mathrm{mM}$ DTT and $150 \mathrm{mM}$ imidizole for $30 \mathrm{~min}$ at $4^{\circ} \mathrm{C}$ with rotation for Cdh1p-6xHis beads or resuspended directly in $25 \mu \mathrm{L}$ of $2.5 \times \mathrm{SB}$ (7.5\% SDS, $287.5 \mathrm{mM}$ sucrose, $162.5 \mathrm{mM}$ Tris- $\mathrm{HCl}$ at pH $6.8,357.5 \mathrm{mM} \beta$-mercaptoethanol) for GST-Cdc20p beads. 6 $\mu \mathrm{L}$ of $5 \times$ SB was added to the eluted samples. For Cdh1p-6xHis samples, $25 \mu \mathrm{L}$ were run on SDS-PAGE for Coomassie staining; 2.5- $\mu \mathrm{L}$ samples were run on SDS-PAGE for immunoblot analysis with $\alpha$-MBP antibodies $(72 \mathrm{ng} / \mathrm{mL})$. For GST-Cdc20p samples, first $5 \mu \mathrm{L}$ were processed for immunoblot analysis with anti-MBP antibodies to detect MBP-Hsl1 $\mathrm{p}^{667-872}$ binding. Then the immunoblot was stripped as described previously (Burton and Solomon 2000) and re-probed with anti-GST antibodies to detect GST-Cdc20p present on the glutathione beads.

\section{Acknowledgments}

We thank David Morgan for the Cdh1p-6xHis baculovirus; Zachary Pitluck for affinity-purified anti-MBP and anti-GST antibodies; Rocco Carbone from The Yale Cancer Center Flow Cytometry Shared Resource (U.S. Public Health Service grant CA-16359) for performing FACS analysis; Vasiliki Tsakraklides for help with the baculovirus work; Adrienne Natrillo for technical assistance; Aiyang Cheng, Mark Hochstrasser, Denis Ostapenko and Vasiliki Tsakraklides for critical reading of the manuscript; and Philipp Kaldis and Karen Ross for insightful discussions. We are grateful to Cathie Pfleger and Marc Kirschner for communication of unpublished results.

This work was supported by a Jane Coffin Childs Fellowship (J.L.B.), grant T32-CA-09159-24 from the NIH awarded to the Molecular \& Oncologic Virology Training Program (J.L.B.), 
grant GM47830 from the NIH (M.J.S.), and grant RPG-98-270 from the American Cancer Society (M.J.S.).

The publication costs of this article were defrayed in part by payment of page charges. This article must therefore be hereby marked "advertisement" in accordance with 18 USC section 1734 solely to indicate this fact.

\section{References}

Amon, A., Irniger, S., and Nasmyth, K. 1994. Closing the cell cycle circle in yeast: G2 cyclin proteolysis initiated at mitosis persists until the activation of G1 cyclins in the next cycle. Cell 77: 1037-1050.

Ausubel, F.M., Brent, R., Kingston, R.E., Moore, D.D., Seidman, J.G., Smith, J.A., and Struhl, K. 1995. Current Protocols in Molecular Biology. John Wiley \& Sons, New York.

Barral, Y., Parra, M., Bidlingmaier, S., and Snyder, M. 1999. Nim1-related kinases coordinate cell cycle progression with the organization of the peripheral cytoskeleton in yeast. Genes \& Dev. 13: 176-187.

Blanco, M.A., Sanchez-Diaz, A., de Prada, J.M., and Moreno, S. 2000. APC $^{\text {ste9/srwl }}$ promotes degradation of mitotic cyclins in G1 and is inhibited by cde2 phosphorylation. EMBO $I$. 19: 3945-3955.

Burton, J.L. and Solomon, M.J. 2000. Hsllp, a Swe1p inhibitor, is degraded via the anaphase-promoting complex. Mol. Cell. Biol. 20: 4614-4625.

Ciechanover, A. 1994. The ubiquitin-proteasome proteolytic pathway. Cell 79: 13-21.

Ciosk, R., Zachariae, W., Michaelis, C., Shevchenko, A., Mann, M., and Nasmyth, K. 1998. An ESP1/PDS1 complex regulates loss of sister chromatid cohesion at the metaphase to anaphase transition in yeast. Cell 93: 1067-1076.

Cohen-Fix, O., Peters, J.M., Kirschner, M.W., and Koshland, D. 1996. Anaphase initiation in Saccharomyces cerevisiae is controlled by the APC-dependent degradation of the anaphase inhibitor Pds1p. Genes \& Dev. 10: 3081-3093.

Deshaies, R.J., Chau, V., and Kirschner, M.W. 1995. Ubiquitination of the G1 cyclin Cln2p by a Cdc34p-dependent pathway. EMBO J. 14: 303-312.

Fang, G., Yu, H., and Kirschner, M.W. 1998a. The checkpoint protein MAD2 and the mitotic regulator CDC20 form a ternary complex with the anaphase-promoting complex to control anaphase initiation. Genes \& Dev. 12: 1871-1883.

Fang, G., Yu, H., and Kirschner, M.W. 1998b. Direct binding of CDC20 protein family members activates the anaphase-promoting complex in mitosis and G1. Mol. Cell 2: 163-171.

Feldman, R.M., Correll, C.C., Kaplan, K.B., and Deshaies, R.J. 1997. A complex of Cdc4p, Skp1p, and Cdc53p/cullin catalyzes ubiquitination of the phosphorylated CDK inhibitor Sic1p. Cell 91: 221-230.

Fisher, R.P., Jin, P., Chamberlin, H.M., and Morgan, D.O. 1995. Alternative mechanisms of CAK assembly require an assembly factor or an activating kinase. Cell 83: 47-57.

Funabiki, H., Yamano, H., Kumada, K., Nagano, K., Hunt, T., and Yanagida, M. 1996. Cut2 proteolysis required for sisterchromatid separation in fission yeast. Nature 381: 438-441.

Gietz, R.D., Schiestl, R.H., Willems, A.R., and Woods, R.A. 1995. Studies on the transformation of intact yeast cells by the LiAc/SS-DNA/PEG procedure. Yeast 11: 355-360.

Glotzer, M., Murray, A.W., and Kirschner, M.W. 1991. Cyclin is degraded by the ubiquitin pathway. Nature 349: 132-138.

Hochstrasser, M. 1996. Ubiquitin-dependent protein degradation. Annu. Rev. Genet. 30: 405-439.
Irniger, S., Piatti, S., Michaelis, C., and Nasmyth, K. 1995. Genes involved in sister chromatid separation are needed for B-type cyclin proteolysis in budding yeast. Cell 81: 269-278.

Jacobs, H.W., Keidel, E., and Lehner, C.F. 2001. A complex degradation signal in Cyclin A required for G1 arrest, and a C-terminal region for mitosis. EMBO J. 20: 2376-2386.

Jaspersen, S.L., Charles, J.F., Tinker-Kulberg, R.L., and Morgan, D.O. 1998. A late mitotic regulatory network controlling cyclin destruction in Saccharomyces cerevisiae. Mol. Biol. Cell 9: 2803-2817.

Jaspersen, S.L., Charles, J.F., and Morgan, D.O. 1999. Inhibitory phosphorylation of the APC regulator Hctl is controlled by the kinase Cdc28 and the phosphatase Cdc14. Curr. Biol. 9: $227-236$.

King, R.W., Deshaies, R.J., Peters, J.M., and Kirschner, M.W. 1996. How proteolysis drives the cell cycle. Science 274: 1652-1659.

Kotani, S., Tanaka, H., Yasuda, H., and Todokoro, K. 1999. Regulation of APC activity by phosphorylation and regulatory factors. J. Cell Biol. 146: 791-800.

Kramer, E.R., Gieffers, C., Holzl, G., Hengstschlager, M., and Peters, J.M. 1998. Activation of the human anaphase-promoting complex by proteins of the CDC20/Fizzy family. Curr. Biol. 8: 1207-1210.

Krek, W. 1998. Proteolysis and the G1-S transition: The SCF connection. Curr. Opin. Genet. Dev. 8: 36-42.

Lew, D.J. and Reed, S.I. 1995. A cell cycle checkpoint monitors cell morphogenesis in budding yeast. J. Cell Biol. 129: 739749.

Lim, H.H., Goh, P.-Y., and Surana, U. 1998. Cdc20 is essential for the cyclosome-mediated proteolysis of both Pds1 and Clb2 during M phase in budding yeast. Curr. Biol. 8: 231234.

Listovsky, T., Zor, A., Laronne, A., and Brandeis, M. 2000. Cdk1 is essential for mammalian cyclosome/APC regulation. Exp. Cell Res. 255: 184-191.

LoRincz, A. and Reed, S.I. 1986. Sequence analysis of temperature-sensitive mutations in the Saccharomyces cerevisiae gene CDC28. Mol. Cell. Biol. 6: 4099-4103.

McMillan, J.N., Longtine, M.S., Sia, R.A.L., Theesfeld, C.L., Bardes, E.S.G., Pringle, J.R., and Lew, D.J. 1999. The morphogenesis checkpoint in Saccharomyces cerevisiae: Cell cycle control of Swelp degradation by Hsllp and Hs17p. Mol. Cell. Biol. 19: 6929-6939.

Mitchell, D.A., Marshall, T.K., and Deschenes, R.J. 1993. Vectors for the inducible overexpression of glutathione S-transferase fusion proteins in yeast. Yeast 9: 715-722.

Ohtoshi, A., Maeda, T., Higashi, H., Ashizawa, S., and Hatakeyama, M. 2000. Human p55/Cde20 associates with cyclin A and is phosphorylated by the cyclin A-Cdk2 complex. Biochem. Biophys. Res. Comm. 268: 530-534.

Patton, E.E., Willems, A.R., and Tyers, M. 1998. Combinatorial control in ubiquitin-dependent proteolysis: Don't Skp the F-box hypothesis. Trends Genet. 14: 236-243.

Peters, J.M. 1998. SCF and APC: The Yin and Yang of cell cycle regulated proteolysis. Curr. Opin. Cell Biol. 10: 759-768.

Peters, J.M. 1999. Subunits and substrates of the anaphase-promoting complex. Exp. Cell Res. 248: 339-349.

Peterson, B.O., Wagener, C., Marinoni, F., Kramer, E.R., Melixetian, M., Denchi, E.L., Gieffers, C., Matteucci, C., Peters, J.M., and Helin, K. 2000. Cell cycle- and cell growth-regulated proteolysis of mammalian CDC6 is dependent on APCCDH1. Genes \& Dev. 14: 2330-2343.

Pfleger, C.M. and Kirschner, M.W. 2000. The KEN box: An APC recognition signal distinct from the $\mathrm{D}$ box targeted by Cdh1. Genes \& Dev. 14: 655-665. 
Pfleger, C.M., Lee, E., and Kirschner, M.W. 2001. Substrate recognition by the Cdc20 and Cdh1 components of the anaphase-promoting complex. Genes \& Dev. 15: 2396-2407 (this issue).

Prinz, S., Hwang, E.S., Visintin, R., and Amon, A. 1998. The regulation of Cdc20 proteolysis reveals a role for APC components Cdc23 and Cdc27 during S phase and early mitosis. Curr. Biol. 8: 750-760.

Schwab, M., Lutum, A.S., and Seufert, W. 1997. Yeast Hct1 is a regulator of Clb2 cyclin proteolysis. Cell 90: 683-693.

Shirayama, M., Zachariae, W., Ciosk, R., and Nasmyth, K. 1998. The Polo-like kinase Cdc5p and the WD-repeat protein Cdc20p/fizzy are regulators and substrates of the anaphase promoting complex in Saccharomyces cerevisiae. EMBO J. 17: $1336-1349$.

Shirayama, M., Toth, A., Galova, M., and Nasmyth, K. 1999. $\mathrm{APC}^{\mathrm{Cdc} 20}$ promotes exit from mitosis by destroying the anaphase inhibitor Pds1 and cyclin Clb5. Nature 402: 203-207.

Shulewitz, M.J., Inouye, C.J., and Thorner, J. 1999. Hs17p localizes to a septin ring and serves as an adaptor in a regulatory pathway that relieves tyrosine phosphorylation of Cdc28 protein kinase in Saccharomyces cerevisiae. Mol. Cell. Biol. 19: 7123-7137.

Skowyra, D., Craig, K.L., Tyers, M., Elledge, S.J., and Harper, J.W. 1997. F-box proteins are receptors that recruit phosphorylated substrates to the SCF ubiquitin-ligase complex. Cell 91: 209-219.

Skowyra, D., Koepp, D.M., Kamura, T., Conrad, M.N., Conaway, R.C., Conaway, J.W., Elledge, S.J., and Harper, J.W. 1999. Reconstitution of $\mathrm{G}_{1}$ cyclin ubiquitination with complexes containing SCF ${ }^{\mathrm{Grrl}}$ and Rbx1. Science 284: 662-665.

Sorensen, C.S., Lukas, C., Kramer, E.R., Peters, J.M., Bartek, J., and Lukas, J. 2001. A conserved cyclin-binding domain determines functional interplay between anaphase-promoting complex-Cdh1 and Cyclin A-Cdk2 during cell cycle progression. Mol. Cell. Biol. 21: 3692-3703.

Stratmann, R. and Lehner, C.F. 1996. Separation of sister chromatids in mitosis requires the Drosophila pimples product, a protein degraded after the metaphase/anaphase transition. Cell 84: 25-35.

Verma, R., Annan, R.S., Huddleston, M.J., Carr, S.A., Reynard, G., and Deshaies, R.J. 1997. Phosphorylation of Siclp by G1 Cdk required for its degradation and entry into S-phase. Science 278: 455-460.

Visintin, R., Prinz, S., and Amon, A. 1997. CDC20 and CDH1: A family of substrate-specific activators of APC-dependent proteolysis. Science 278: 460-463.

Yamamoto, A., Guacci, V., and Koshland, D. 1996. Pds1p is required for faithful execution of anaphase in the yeast, Saccharomyces cerevisiae. J. Cell Biol. 133: 85-97.

Zachariae, W. and Nasmyth, K. 1999. Whose end is destruction: Cell division and the anaphase-promoting complex. Genes \& Dev. 13: 2039-2058.

Zachariae, W., Schwab, M., Nasmyth, K., and Seufert, W. 1998. Control of cyclin ubiquitination by CDK-regulated binding of Hctl to the anaphase promoting complex. Science 282: 1721-1724.

Zou, H., McGarry, T.J., Bernal, T., and Kirschner, M.J. 1999. Identification of a vertebrate sister-chromatid separation inhibitor involved in transformation and tumorigenesis. Science 285: 418-422.

Zur, A. and Brandeis, M. 2001. Securin degradation is mediated by fzy and fzr, and is required for complete chromatid separation but not for cytokinesis. EMBO I. 20: 792-801. 


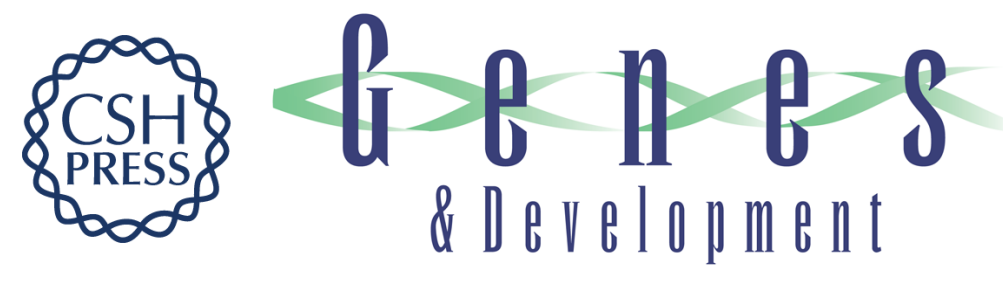

\section{$D$ box and KEN box motifs in budding yeast Hsl1p are required for APC-mediated degradation and direct binding to Cdc20p and Cdh1p}

Janet L. Burton and Mark J. Solomon

Genes Dev. 2001, 15:

Access the most recent version at doi:10.1101/gad.917901

References This article cites 53 articles, 26 of which can be accessed free at:

http://genesdev.cshlp.org/content/15/18/2381.full.html\#ref-list-1

License

Email Alerting Receive free email alerts when new articles cite this article - sign up in the box at the top Service right corner of the article or click here.

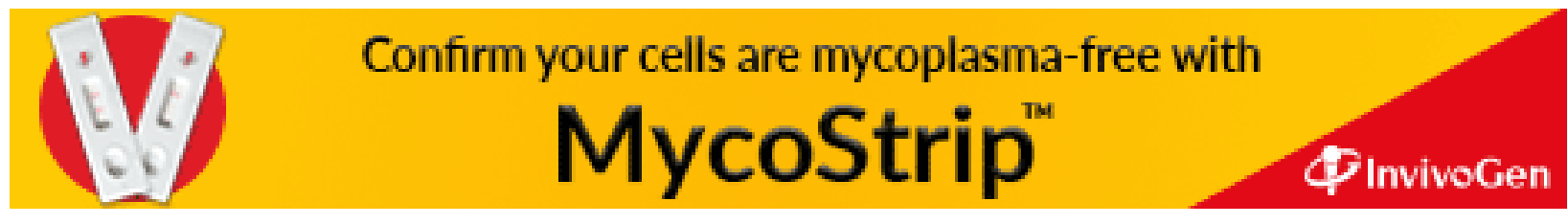

